\title{
Quasi-biweekly oscillation of the Asian monsoon rainfall in late summer and autumn: different types of structure and propagation
}

\author{
Xin Yan ${ }^{1,2} \cdot$ Song Yang ${ }^{1,2,3}$. Teng Wang ${ }^{1} \cdot$ Eric D. Maloney ${ }^{4} \cdot$ Shaorou Dong ${ }^{5} \cdot$ Wei Wei $^{1,2} \cdot$ Shan He ${ }^{1}$
}

Received: 6 December 2018 / Accepted: 20 August 2019 / Published online: 26 August 2019

(c) The Author(s) 2019

\begin{abstract}
This study contrasts two types of quasi-biweekly oscillations (QBWOs) over tropical Asia in late-summer and autumn (from August to October). Using a tracking method to calculate the frequency of QBWO events over the Asian monsoon region, two types of QBWOs in monsoon rainfall are revealed. One originates from $110^{\circ}$ to $140^{\circ} \mathrm{E}$ and propagates westward to southern China with a notable impact on the regional rainfall, while the other initiates from $160^{\circ} \mathrm{E}$ to the dateline and does not affect southern China rainfall significantly. Analysis of the vertical structure of moisture flux shows that the moisture source for type 1 events is dominated by the zonal flux component and that for type 2 the meridional flux component. The nature of the moisture flux determines whether the oscillation can propagate across $120^{\circ} \mathrm{E}$ and affect rainfall over southern China. Results also show that the strength of the South Asian high and the western Pacific subtropical high differently modulate the generation of the two types of QBWOs. Specifically, mutually stronger (weaker) highs favor the first (second) type of the oscillation. A close relationship also exists between the QBWOs and western Pacific sea surface temperature (SST) anomalies, suggesting that the SST anomalies can potentially trigger the QBWOs.
\end{abstract}

Keywords Quasi-biweekly oscillation · Intraseasonal variability · Boreal summer intraseasonal oscillation · Asian monsoon

\section{Introduction}

Two dominant intraseasonal oscillation (ISO) modes exist in the Asian summer monsoon system: a 10-20-day oscillation, which is also called the quasi-biweekly oscillation (QBWO), and a 30-60-day oscillation. The QBWO was perhaps first discovered over the Indian Ocean region (Keshavam 1971; Keshavamurty 1972). It propagates westward and is closely linked to activity (e.g., active and inactive periods) of the

Song Yang

yangsong3@mail.sysu.edu.cn

1 School of Atmospheric Sciences, Sun Yat-sen University, 135 West Xingang Road, Guangzhou 510275, China

2 Guangdong Province Key Laboratory for Climate Change and Natural Disaster Studies, Sun Yat-sen University, Guangzhou, China

3 Institute of Earth Climate and Environment System, Sun Yat-sen University, Guangzhou, China

4 Department of Atmospheric Science, Colorado State University, Fort Collins, CO, USA

5 Guangdong Climate Center, CMA Guangdong Provincial Meteorological Bureau, Guangzhou, China monsoon. Previous studies have compared the QBWO with the 30-60-day oscillation and found many differences between the two modes (Chen and Chen 1993, 1995; Chen et al. 2000; Annamalai and Slingo 2001; Yokoi et al. 2007; Yang et al. 2008; Li et al. 2015). Wang et al. (2009) revealed that the quasi-biweekly and 30-60-day modes of intraseasonal variation are characterized by different source regions and life cycles. However, compared to the Madden-Julian Oscillation (MJO) and other 30-60-day oscillations (Zhang et al. 2013; Ling et al. 2017a, b), the characteristics of QBWOs are much less understood, especially when considering the maintenance mechanisms and the effects of the QBWO on weather and climate outside the tropics.

Figure 1 exhibits the variance of quasi-biweekly filtered GPCP rainfall (contours) and the ratio of quasi-biweekly variance to 30-60-day variance (shading) during latesummer and autumn (August to October, or ASO) for 1997-2014. As the shading shows, in most parts of the Asian monsoon region, QBWO variance is much larger than that of 30-60-day variability. The maximum variance of QBWOs (contours) appears in regions of active Asian monsoon convection. Large centers are located in the Bay of Bengal, the South China Sea, and the western Pacific Ocean. Especially 
Fig. 1 Variance of quasibiweekly rainfall (contour; interval $20 \mathrm{~mm}^{2} / \mathrm{day}^{2}$ ) and ratio of QBWO variance to 30-60day variance (shading) during late-summer and autumn (from August to October)

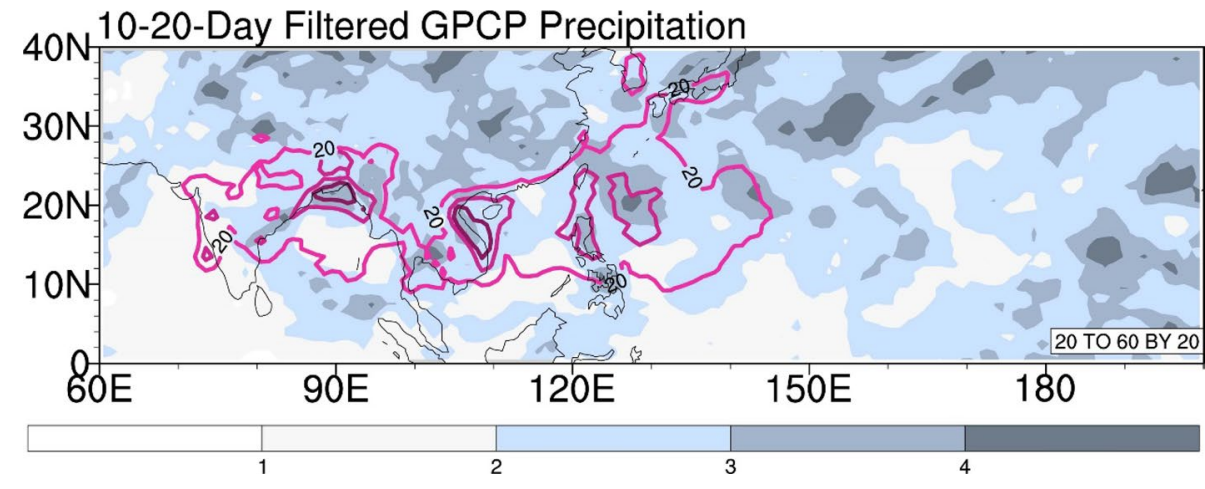

noteworthy is that the ratio of variance is about 3 (grey shading) in the active QBWO center, indicating that the variance of QBWOs is dominant over the Asian monsoon region. Similar behavior can also be found in the spring season [see Fig. 4 in Wen and Zhang (2008)]. Although QBWO variance is larger than variance associated with the 30-60-day oscillation in the tropics, it may not be as spatially coherent. Many studies, especially those based on empirical orthogonal function (EOF), do not show a 10-20-day oscillation as the leading EOF mode. For example, Lin (2012) found that the first two modes of outgoing longwave radiation (OLR) and winds represented the 30-60-day oscillation and the next two modes were related to QBWOs. Lee et al. (2013) also found that the first two EOF modes in the boreal summer intraseasonal oscillation index were consistent with the 30-60 day mode and the fourth mode was has timescale of the QBWO (the third mode was dominated by 20-30 day variability). Due to the orthogonality of EOF modes, the physical meaning of the third and fourth modes was limited. Therefore, EOF methods may not be the most suitable tool for studying QBWOs. In addition to the EOF analysis, tracking methods are often used to study intraseasonal oscillations. For MJO events, Kerns and Chen (2016) used a twodimensional (2D) method that could track convective centers in both longitude and latitude. Zhang and Ling (2017) defined a one-dimensional (1D) method that only focuses on zonal propagation in longitude. For QBWO events, Kikuchi and Wang (2009) used a 2D method to track QBWOs from a global perspective. There are relatively fewer studies using tracking methods to investigate QBWOs than 30-60 day variability. Since QBWO events are more irregular, and propagate both eastward and westward (Kikuchi and Wang 2009), it is more difficult to track and monitor the QBWO than longer timescale intraseasonal disturbances such as the MJO, including the development of EOF-based indices to monitor such events. Tracking methods provide advantages over EOF-based methods for detection and monitoring of ISO events. For example, tracking methods currently used in MJO studies can better capture quantitative information about the MJO compared to the traditional EOF analysis. In particular, tracking methods provide a more detailed analysis of the source, frequency, intensity, and propagation distance of these oscillations (Ling et al. 2017a, b). Following Zhang and Ling (2017), we applied a 1-D tracking method to analyze QBWO events that tracks these events in longitude, complementing the 2D tracking method of Kikuchi and Wang (2009).

QBWO activity is clearly seasonal and regional, much like for the 30-60 day boreal summer ISO where the climatological propagation characteristics of convective anomalies in the Indian Ocean to western Pacific are quite different from May to June (MJ) that during ASO (Kemball-Cook and Wang 2001). In the Asian monsoon region, the summer QBWO propagates westward, and the main genesis region for disturbances is the western Pacific Ocean (Kikuchi and Wang 2009; Jia and Yang 2013). Fukutomi and Yasunari (1999) noted that on the time scale of 10-25 days, convection was associated with well-organized low-level cyclonic circulation anomalies over the South China Sea. Annamalai and Slingo (2001) showed that QBWO is more regional than 30-60 day variability, and the QBWO is mainly generated in the western Pacific with prominent zonal propagation. The propagation characteristics of the QBWO vary substantially with month of the year given its diverse origins in different seasons (Wen and Zhang 2008; Chen and Sui 2010; Wen et al. 2010). Although extra-tropical processes over land can affect the intraseasonal variability of monsoon rainband (Wang et al. 2017b), Wang et al. (2017a) showed that the boreal summer QBWO in the Asian monsoon region has its primary origins in the western equatorial Pacific and it propagates northwestward into the Bay of Bengal. Therefore, we focus on the QBWO in the Asian monsoon region in this study. While the study of Kikuchi and Wang (2009) emphasized global behavior of QBWOs, here we focus on regional QBWO events that begin in the western Pacific and propagate westward.

The paper is organized as follows. In Sect. 2, we describe the data sets and methodology. We modify the MJO tracking method of Zhang and Ling (2017) for use in tracking QBWO events. In Sect. 3, the propagation characteristics and 
vertical structures of two types of QBWOs are discussed. In Sect. 4, the large-scale circulation anomalies associated with QBWOs are investigated. Summary and discussion are given in Sect. 5.

\section{Data and methodology}

\subsection{Data}

To represent QBWO events in Asian monsoon rainfall, we use daily rainfall data from 1996 to 2015 from the Global Precipitation Climatology Project, version 1.2 (Huffman et al. 2001, 2016), with a horizontal resolution of $1^{\circ} \times 1^{\circ}$. ERA-Interim data from the European Centre for Mediumrange Weather Forecasts (Simmons et al. 2007) with a resolution of $0.75^{\circ} \times 0.75^{\circ}$ are used to study dynamic and thermodynamic atmospheric fields during QBWO events. We also use daily sea surface temperature (SST) derived from the NOAA high-resolution $\left(0.25^{\circ} \times 0.25^{\circ}\right)$ blended analysis, OISSTV2 (National Climatic Data Center 2007; Reynolds et al. 2007; Banzon and Reynolds 2013), which includes daily SST and sea ice. The Real-time Multivariate MJO (RMM) index of Wheeler and Hendon (2004) is used to analyze the relationship between the QBWO and MJO. The RMM index is derived using a multivariate EOF analysis on equatorial wind anomalies in the upper and lower troposphere and outgoing longwave radiation anomalies.

\subsection{Tracking method}

As discussed earlier, EOF analysis is more suitable for MJO study (e.g. Lin 2012; Lee et al. 2013; Maloney et al. 2014) than for QBWO study, since the first two EOF modes derived from unfiltered anomalies are dominated by 30-60 day variability. Considering that QBWOs have higher variance but are less spatially-coherent, tracking methods seems to be a more effective means of analyzing the QBWO. Following the method of Zhang and Ling (2017), which objectively identified the eastward movement of positive rainfall anomalies along the equator, we track the QBWO using GPCP rainfall anomalies. This method focuses primarily on 1D motion in longitude. The method of Zhang and Ling is able to provide several characteristics of the identified events (Fig. 2 in Zhang and Ling 2017), such as the starting longitude and time, ending longitude and time, propagation speed and range, strength, life span, and zonal scale. These quantities are not provided by conventional EOF-based indices. The Zhang and Ling (2017) method could also be conceivably used in other tropical or extra-tropical wave disturbances. For example, easterly waves or convectively coupled Rossby waves could be tracked by changing the settings of the tracking method or by preprocessing the data to preselect certain wavenumbers and frequencies.

The tracking method is introduced point by point in Zhang and Ling (2017), which we will only briefly summarize here. There are three main steps in the method: data preparation, a six-step process to track movement of the anomalies, and then a final selection step consisting of three criteria (propagation range, propagation speed, interval between events). In our study, most of them are still suitable. To apply the method to QBWOs over the Asian monsoon region, we modify the Zhang and Ling (2017) method as follows:

- In the data preparation stage, the original tracking method uses the fast Fourier transform (Gottschalck et al. 2013) to obtain eastward-propagating intraseasonal (20-100-day) precipitation signals using equatorial symmetric data. Since the strongest QBWO signals in summer are over the Asian monsoon region (not equatorially symmetric), we replace the fast Fourier transform with the Lanczos filtering (Duchon 1979) to get 10-20 day subseasonal signals.

- After filtering, rainfall anomalies are averaged between $10^{\circ}-25^{\circ} \mathrm{N}$.

- For better identifying the tracking lines which show QBWO events, nine-point local smoothing is performed as the last step of data preparation.

- In the tracking stage, the analysis domain is from $40^{\circ} \mathrm{E}$ to $160^{\circ} \mathrm{W}$.

- Only data from late summer to early autumn (from August to October) are used for 1997-2015.

- The interval between two tracked events is required to be longer than 5 days (for MJO, its interval is from 20 to 25 days), with characteristics of propagation speed and range discussed in more detail below.

- Considering that the QBWO primarily originates over the western Pacific and propagates westward (Kikuchi and Wang 2009), we set a reference longitude to $120^{\circ} \mathrm{E}$ for effectively identifying MJO events over the western Pacific (about $90^{\circ} \mathrm{E}$ in Zhang and Ling 2017) and only track westward movement. Because of this, all tracking lines will be positive.

\subsection{Other analysis methods}

Lanczos filtering (Duchon 1979) is applied to extract QBWO signals from OLR and atmospheric circulation fields based on a 10-20-day filtering window. For the 10-20-day oscillation, a Lanczos digital filter with 61 daily weight coefficients would provide a sharp cutoff response with negligible Gibbs oscillation. In addition, a composite analysis approach is applied to investigate the large-scale features associated with 
the QBWOs. The Student's $t$ test is used to assess the statistical significance of the results obtained.

\section{Propagation and vertical structures of QBWO}

\subsection{Definitions of QBWO types and their propagation characteristics}

Using the tracking method defined in Sect. 2, we identified a total of 88 events from the 1997-2015 rainfall data. We first obtained statistics about propagation speed, propagation range, and zonal scale, and then removed irrelevant events on this basis (see "Conclusions and discussion" below).

Most frequently the speed of tracked events (Fig. 2a) is between $-5 \mathrm{~m} \mathrm{~s}^{-1}$ and $-3 \mathrm{~m} \mathrm{~s}^{-1}$ with an average speed of
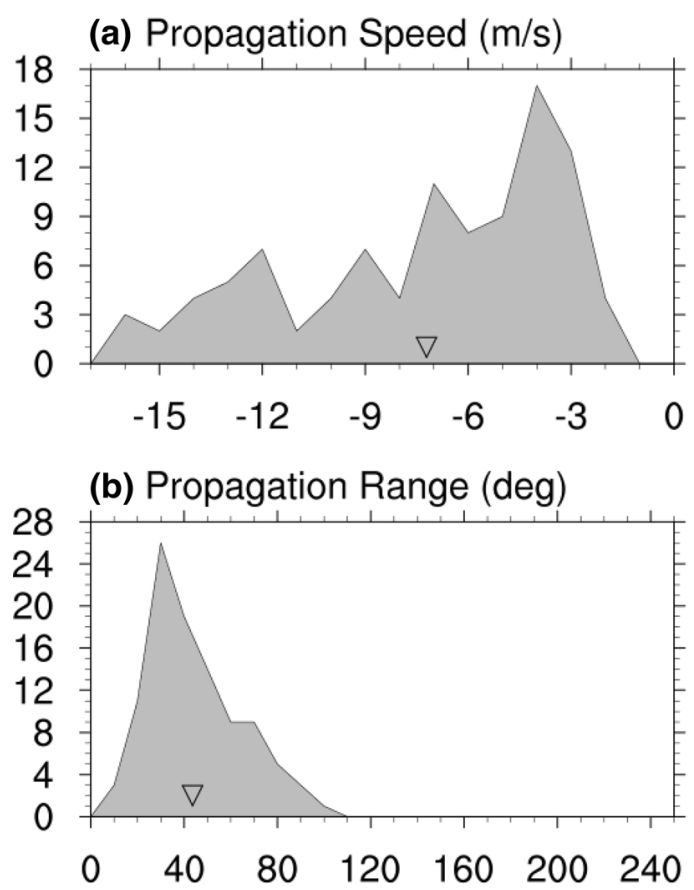

(c) Zonal Scale (deg)

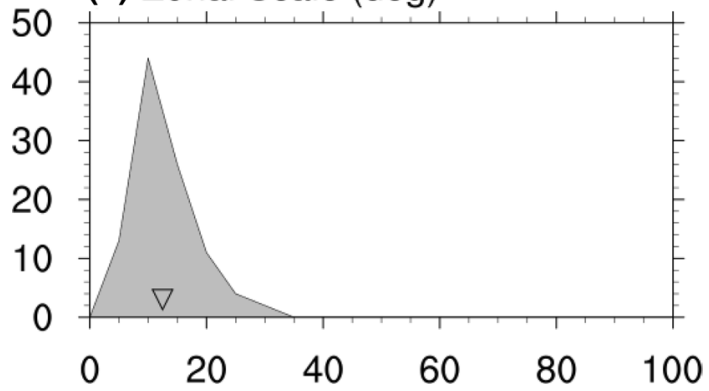

Fig. 2 Distributions of a propagation speed, $\mathbf{b}$ propagation range, and c averaged zonal scale of all tracked westward QBWO events based on GPCP data. Triangle marks the mean about $-7 \mathrm{~m} \mathrm{~s}^{-1}$ (negative value means westward propagation), a bit faster than that of the MJO which has an average speed about $+5 \mathrm{~m} \mathrm{~s}^{-1}$ (see Fig. 3 of Zhang and Ling 2017). Second, the most frequent propagation range of events (Fig. $2 \mathrm{~b}$ ) is about $40^{\circ}$. Few events have a propagation range of more than $80^{\circ}$. For MJO events, the propagation range can exceed $120^{\circ}$. This result confirms that QBWO events are more regional compared to the $\mathrm{MJO}$, which has a more global character. Further, the dominant zonal scale of QBWO precipitation (Fig. 2c) is between $10^{\circ}$ to $20^{\circ}$ and that of MJO events is about $30^{\circ}$, which is about twice that of the QBWO.

Based on the aforementioned QBWO attributes, we chose QBWO events with westward propagation speed between $2 \mathrm{~m} \mathrm{~s}^{-1}$ and $10 \mathrm{~m} \mathrm{~s}^{-1}$, which results in 21 events $(23.9 \%)$ being excluded. We also choose events with propagation distance greater than $20^{\circ}$, which resulted in the exclusion of an additional 11 events (12.5\%). A total of 59 QBWO events are thus retained in our analysis.

To further explore the characteristics of the selected QBWO events, such as the starting and ending longitudes, propagation speed, range, and strength, individual and joint frequency distributions are provided (see Fig. 3). The starting longitudes of QBWO events cluster in two different regions (Fig. 3a). One region is $110^{\circ}-140^{\circ} \mathrm{E}$ (the South China Sea) and the other is from $150^{\circ} \mathrm{E}$ to the dateline (the western Pacific). The joint frequency distributions indicate that the starting and ending longitudes are strongly correlated, with a correlation coefficient of 0.69. As mentioned above, these events propagate on average about $40^{\circ}$ of longitude (Fig. 2b). The QBWO events that originate in the South China Sea end primarily between $60^{\circ}$ and $90^{\circ} \mathrm{E}$ (the Indian Ocean), while those originating in the western Pacific end primarily between $110^{\circ}$ and $130^{\circ} \mathrm{E}$ (the South China Sea). In addition, a few QBWO events generated between $170^{\circ} \mathrm{W}$ and $160^{\circ} \mathrm{W}$ disappear in the western Pacific. The average strength is defined as the rain rate averaged along a track the starting to end point. The strength of QBWO events is distributed over a range of $2-5 \mathrm{~mm} /$ day (Fig. $3 b$ ), regardless of whether the events originate from the South China Sea or the western Pacific. However, the ones that originate between $170^{\circ} \mathrm{W}$ and $160^{\circ} \mathrm{W}$ are weaker. Further, a clear connection exists between QBWO strength and its zonal scale (Fig. 3c), although there is no well-defined connection between the propagation range and zonal scale (Fig. 3d).

Intraseasonal oscillations such as the QBWO are closely related to the East Asian monsoon rainfall (Lau et al. 1988). Therefore, to understand how QBWO events that originate in the western Pacific affect the climate in the East Asian monsoon region, we use the starting longitude (Fig. 3a) as a criterion to define two types of QBWO events for the subsequent analysis. Among the total of 59 QBWO events, the events with a starting longitude between $110^{\circ} \mathrm{E}$ and $140^{\circ} \mathrm{E}$ 
Fig. 3 Individual and joint frequency distributions of a starting longitude (units: degree) vs ending longitude: b starting longitude vs mean strength (units: $\mathrm{mm} /$ day), c mean zonal scale (units: degree) vs mean strength, and $\mathbf{d}$ mean zonal scale vs propagation range of tracked QBWO events
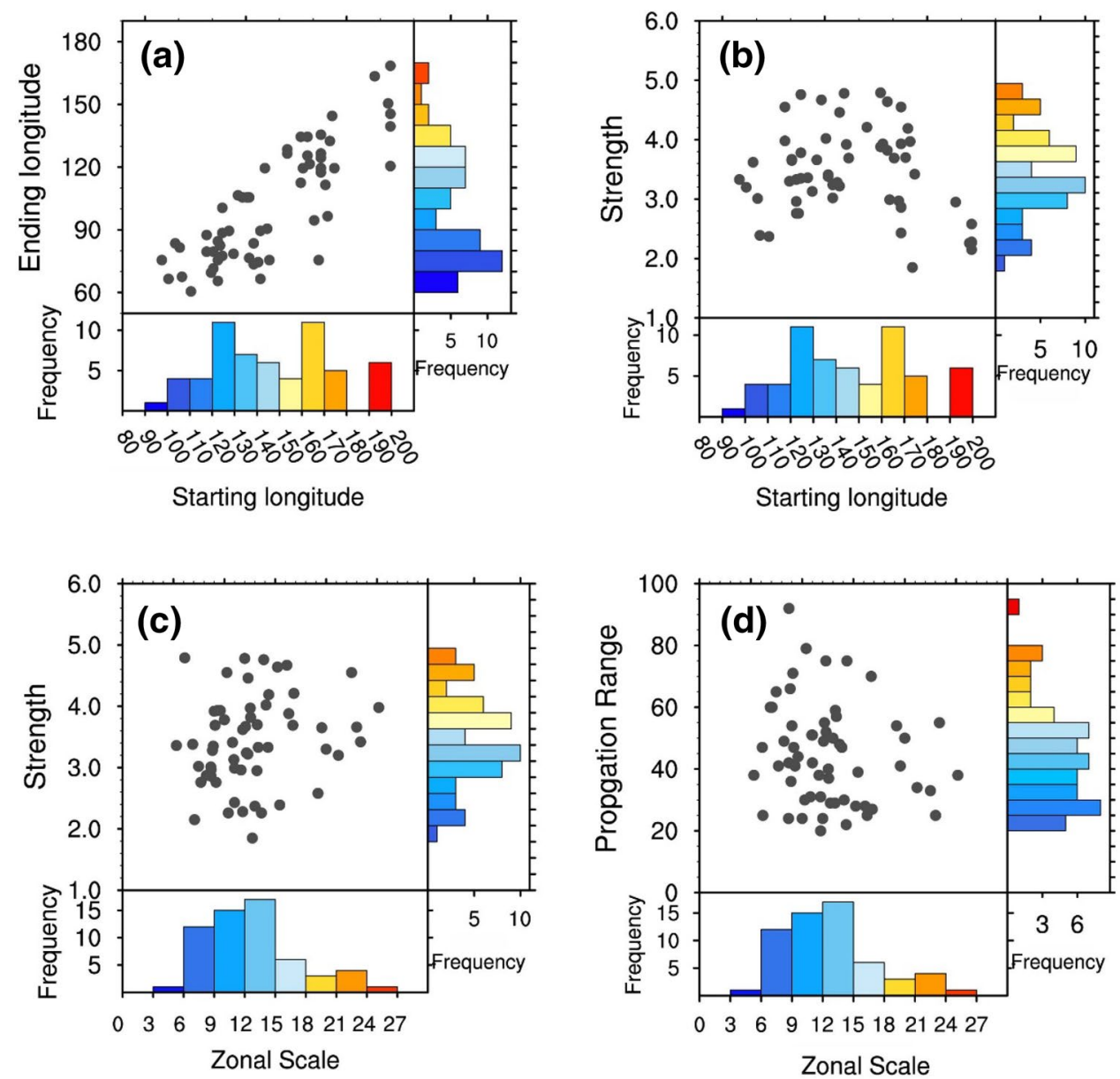

are defined as type 1 , and those with a starting longitude between $150^{\circ} \mathrm{E}$ and the dateline are defined as type 2 . Using these definitions, 22 type- 1 events and 20 type- 2 events are defined. To better illustrate the westward propagation of the two types of QBWOs, longitude-time sections of 10-20-day filtered precipitation composites are shown (Fig. 4). The composite type- 1 events originate at $140^{\circ} \mathrm{E}$ and end to the east of $90^{\circ} \mathrm{E} 12$ days later (Fig. $4 \mathrm{a}$ ). The most prominent propagation occurs in the South China Sea. The main propagation region of type- 2 events occurs over the Philippine Sea and lasts for about 10 days (Fig. 4b).

\subsection{Three dimensional QBWO structure}

Comparing the two types of QBWO indicates several important structural differences at initiation. At day 0 for the type-1 events (Fig. 5a), a negative rainfall anomaly near Vietnam is accompanied by an anti-cyclonic circulation. A positive rainfall anomaly occurs in the western Philippine Sea, accompanied by a cyclonic circulation. For the type- 2 events (Fig. 5b), the center of positive rainfall anomaly is weighted more toward the east side of the cyclonic circulation than for the type-1 disturbances, associated with southwesterly anomalies. The northeasterly wind anomaly between the cyclonic and anti-cyclonic circulations that extends into the Philippines is associated with suppressed rainfall.

Moisture flux convergence for the two types of QBWO disturbances is examined next. The most intense centers of both types of QBWOs occur mainly over the band of $15^{\circ}-20^{\circ} \mathrm{N}$ (Fig. 5). Hence, Fig. 6 shows a longitude-height cross-section of the moisture flux convergence and wind anomalies averaged between $15^{\circ}$ and $20^{\circ} \mathrm{N}$ at day 0 . Consistent with previous observations, at the initiation of type- 1 events, total moisture flux convergence (Fig. 6a) is mainly focused in the eastern Philippines $\left(120^{\circ}-130^{\circ} \mathrm{E}\right)$ and accompanied by strong upward motion, while the corresponding sinking branch is near the Indo-China Peninsula $\left(110^{\circ} \mathrm{E}\right)$. This moisture flux convergence anomaly is mainly provided by its zonal (Fig. 6b) and vertical (Fig. 6d) flux convergence components. However, the positive moisture convergence anomaly of type-2 disturbances (Fig. 6e) occurs over the ocean in the region of $140^{\circ}-160^{\circ} \mathrm{E}$, accompanied by strong upward motion, while the corresponding sinking branch is located near $130^{\circ} \mathrm{E}$. The moisture flux convergence of type- 2 
(a) Type 1
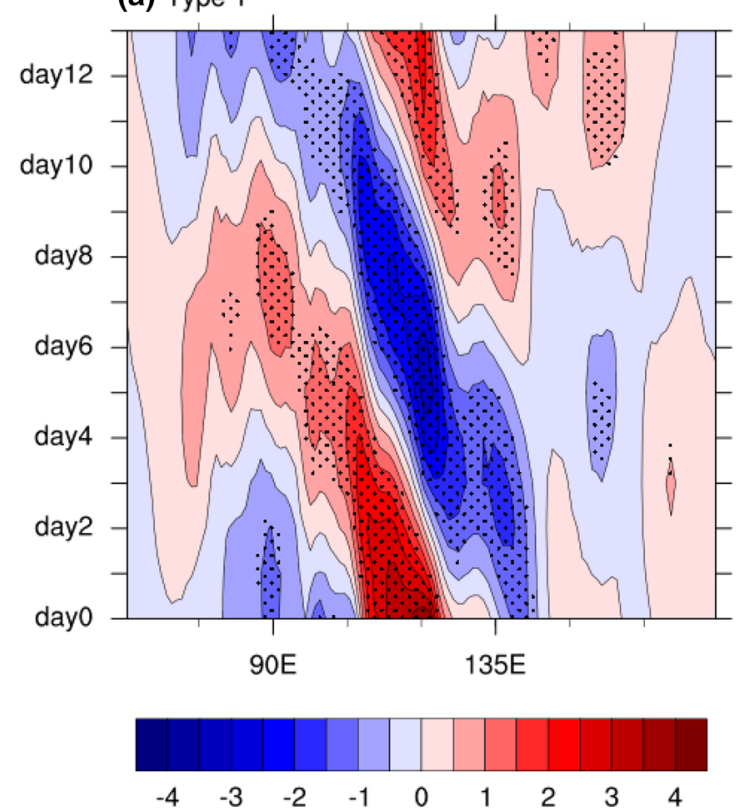

(b) Type 2
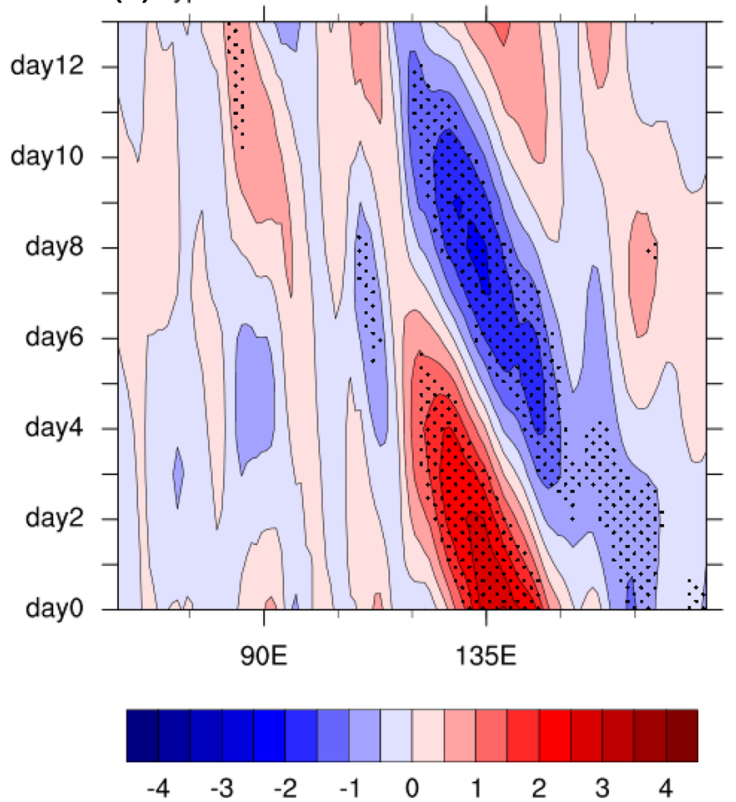

Fig. 4 Longitude-time section (averaged for $10^{\circ} \mathrm{N}-25^{\circ} \mathrm{N}$ ) of 10 -20-day filtered precipitation anomalies of type 1 (a) and type 2 (b). Only significant values above the $95 \%$ confidence level are highlighted
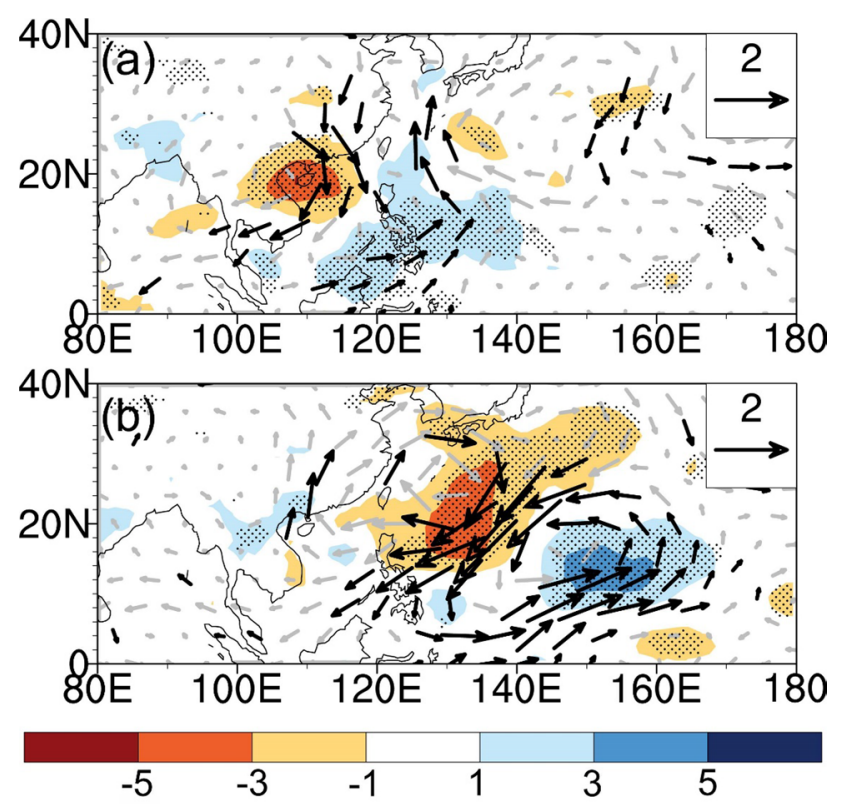

Fig. 5 Maps of 10-20-day filtered precipitation (shading; units: $\mathrm{mm} /$ day) and 850 -hPa wind (vector; units: $\mathrm{m} \mathrm{s}^{-1}$ ) anomalies at day 0 for type 1 (a) and type 2 (b). Only the significant values above the $95 \%$ confidence level are highlighted

QBWOs is dominated by the meridional (Fig. 6g) and vertical (Fig. 6h) components. We note that cause and effect regarding precipitation and moisture flux convergence anomalies is difficult to determine, since the heating associated with convection can drive tropical convergence anomalies (e.g. Neelin and Held 1987). However, dry dynamical considerations have been documented to be important for driving vertical motion that focuses convection in some disturbances (e.g. Kiladis et al. 2006; Rydbeck and Maloney 2015).

Note that significant difference in positive anomalies occurs near $120^{\circ} \mathrm{E}$ east of the Philippines, where the type- 1 QBWO originates (Fig. 5a) and propagates to mainland China, and the type-2 QBWO weakens and disappears (Fig. 5b). We plot the $105^{\circ}-115^{\circ} \mathrm{E}$ averaged latitude-height cross-section to present the downward branch of the type 1 QBWO, and the $120^{\circ}-130^{\circ} \mathrm{E}$ averaged latitude-height crosssection to present the upward branch (Fig. 7). For the type 2 QBWO, we plot the $125^{\circ}-135^{\circ} \mathrm{E}$ and $120^{\circ}-130^{\circ} \mathrm{E}$ averages to present the downward and upward branches, respectively (Fig. 8). The leading moisture convergence is mainly provided by the zonal component for type 1 (Fig. 7f), and by the meridional component for type 2 (Fig. 8g) QBWO disturbances. It is worth noting that the source of water vapor in the middle-upper atmospheres for both type 1 and type 2 are provided by vertical moisture flux (Figs. $7 \mathrm{~h}, 8 \mathrm{~h}$ ), although cause and effect relative to precipitation anomalies is difficult to determine from this analysis. In general, the structures of type-1 and type-2 QBWOs are different, and the generation mechanisms of the two types may also be different. 
Fig. 6 Composite patterns of $15^{\circ}-20^{\circ} \mathrm{N}$ averaged longitudinal-height cross-section of moisture flux convergence (shading; units: $10^{-5} \mathrm{~g} \mathrm{~kg}^{-1} \mathrm{~s}^{-1}$ ) and wind field (vector; units: $\mathrm{m} \mathrm{s}^{-1}$ ) anomalies for type 1 (left) and type 2 (right) disturbances. (a, e), $(\mathbf{b}, \mathbf{f}),(\mathbf{c}, \mathbf{g})$, and $(\mathbf{d}, \mathbf{h})$ are for total, zonal, meridional, and vertical moisture flux convergence components, respectively. Vertical velocities are scaled by a factor of 250 for visualization. $95 \%$ significance stippling is shown (a) total

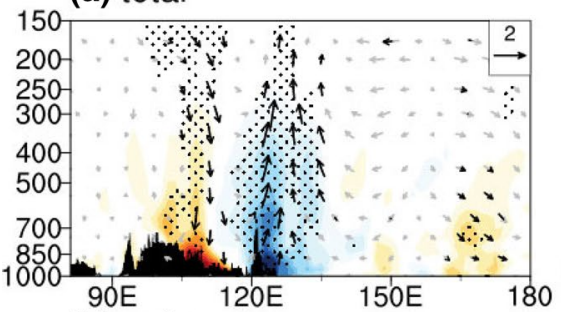

(b) $u q / x$

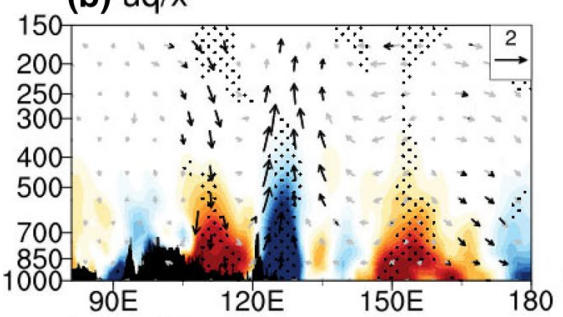

(c) $\mathrm{vq} / \mathrm{y}$

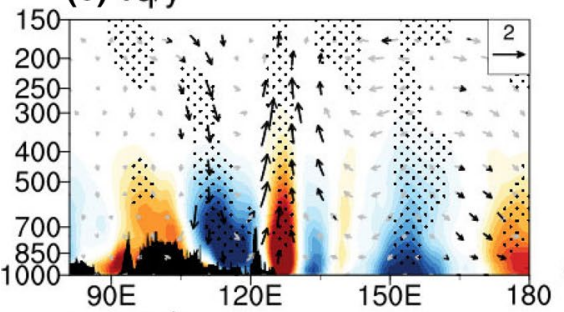

(d) $\mathrm{wq} / \mathrm{p}$

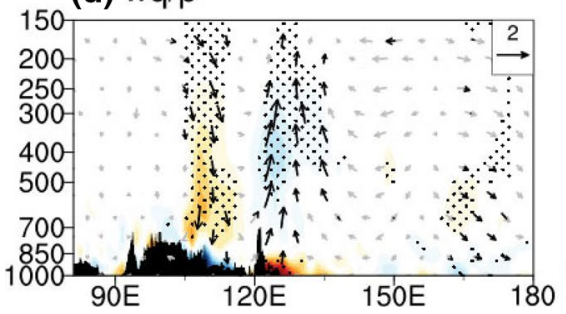

(e) total

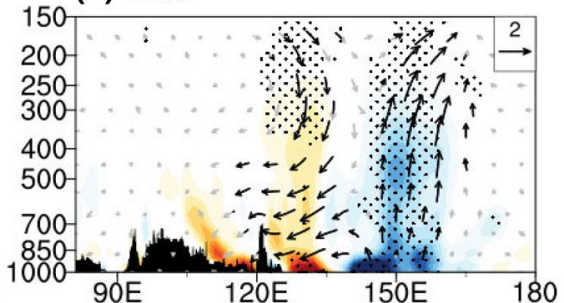

(f) $u q / x$

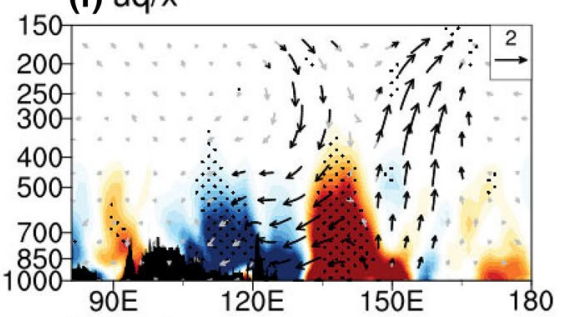

0.6

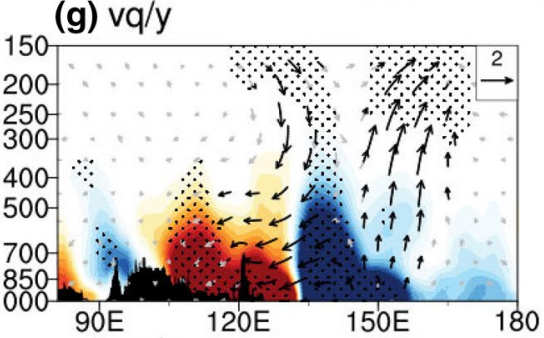

(h) $w q / p$

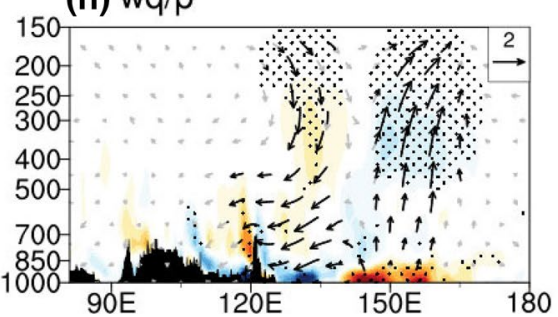

\subsection{Life cycles of QBWO events}

A lagged composite analysis of 10-20-day filtered precipitation and $850-\mathrm{hPa}$ wind anomalies illustrates the life cycles of the two types of QBWOs. The left column of Fig. 9 presents the life cycle of the type-1 QBWOs. On day 0 , the negative anomaly of rainfall occurs in the Beibu Gulf, while the positive anomaly appears to the east of the Philippines (Fig. 9a). This positive anomaly propagates westward and becomes stronger over the South China Sea with an associated cyclonic circulation (Fig. 9b-c). The positive anomaly then reaches the Indo-China Peninsula and southern China (Fig. 9d). On day 8 (Fig. 9e), the positive anomaly weakens over northern Vietnam, and a negative rainfall anomaly appears near $120^{\circ} \mathrm{E}$. The evolution shown in Fig. 9e-h for days 8 to 14 is quite similar to that from day 0 to day 6 (Fig. 9a-d), but with opposite sign. The right column of Fig. 9 shows the life cycle of type 2 QBWOs. The starting longitude for type 2 (Fig. 9i) QBWO events is further eastward than that for type 1 (Fig. 9a). On day 0 (Fig. 9i), a negative anomaly of rainfall occurs at $140^{\circ}-160^{\circ} \mathrm{E}$, while a positive anomaly emerges east of the Philippines. From day 0 to day 6 (Fig. 9i-1), the positive rainfall center moves westward from the western Pacific. It strengthens and eventually reaches the South China Sea. From day 8 onward (Fig. 9m), the positive rainfall center continues to propagate westward but gradually weakens. The positive rainfall anomaly fades and disappears when the disturbance propagates to the south of Japan (Fig. 9n-p). The southwest-northeast tilted wind structure of type 2 QBWO disturbances in this study also bear some resemblance to the synoptic-scale disturbances described in Lau and Lau (1992).

Previous results using EOF-based methods have indicated that QBWOs originate mainly near $160^{\circ} \mathrm{E}$ and strong QBWOs can propagate to $110^{\circ} \mathrm{E}$. An important finding from our study is that the QBWO events generated near $160^{\circ} \mathrm{E}$ are not necessarily linked to those events that initiate and propagate near $110^{\circ} \mathrm{E}$. There are two kinds of QBWO events with different origins, propagation paths, and ranges of influence. 
Fig. 7 Same as the left panels of Fig. 6, except for a latitudinal-height cross-section of type 1 disturbances. The left column is for terms averaged over $105^{\circ}-115^{\circ} \mathrm{E}$, and the right, over $120^{\circ}-130^{\circ} \mathrm{E}$
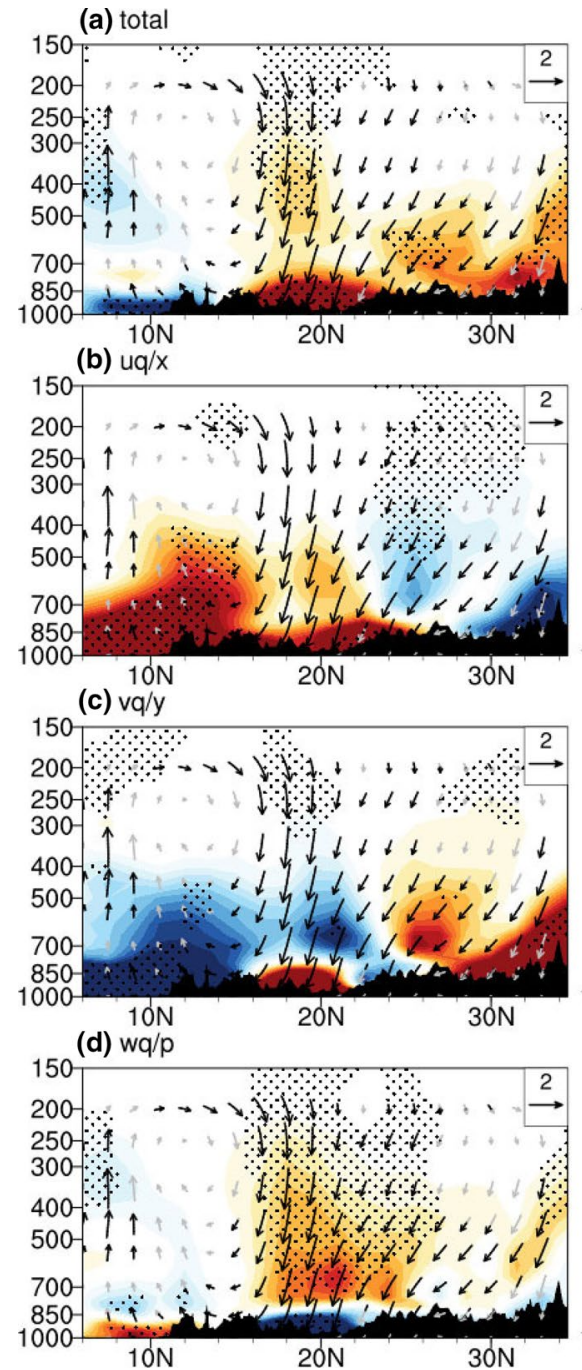

(e) total
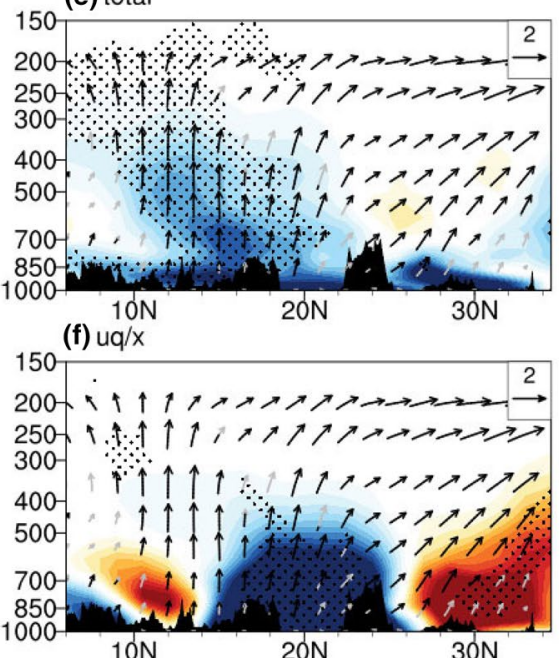

(g) $\mathrm{vq} / \mathrm{y}$

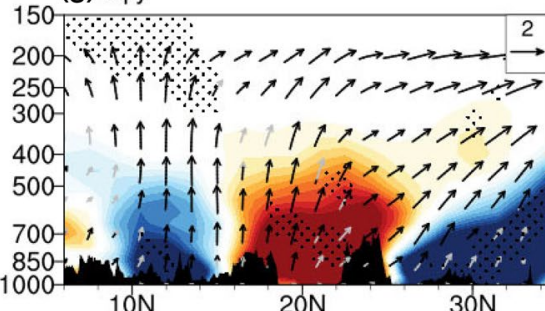

(h) $w q / p$

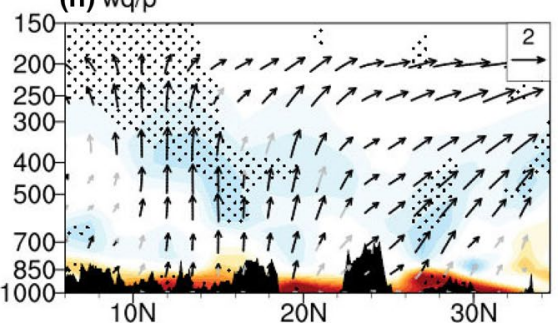

1
The positive anomaly of the type-1 QBWO propagates to East Asia where it affects precipitation before decaying. However, the positive anomaly of the type-2 QBWO decays over the topography of the Philippine Islands, and has little effect on mainland Asia. Comparing these two types of QBWO events, topography and interaction with land may be important factors in determining the propagation of QBWOs.

\section{Variation of large-scale features associated with QBWO propagation}

\subsection{Relationships with western Pacific subtropical high and South Asia high}

The western Pacific subtropical high (WPSH) and the South Asia high (SAH) are two important systems related to the Asian summer monsoon. Previous have studies suggested that variability of the WPSH and SAH can affect the Asian summer monsoon, and it is logical to expect an influence on QBWOs since they are also an integral part of precipitation variability in this region. Yang et al. (2014) found that the SAH and the WPSH, which influence the evolution of QBWOs, move toward (away from) each other in early (late) summer. Wang et al. (2016) suggested that the intensity and extent of the WPSH might affect the evolution and propagation of QBWOs by modulating the occurrence and characteristics of convection. To further explore the interactions between the different types of QBWOs and the large-scale circulation, we now focus on WPSH and the SAH variations on both 10-20-day and climatological time scales in the context of their interactions with QBWOs.

As many tropical systems exhibit a prominent baroclinic structure, we first compare the characteristics of 10-20 day geopotential height anomalies at $200 \mathrm{hPa}$ and $850 \mathrm{hPa}$. With the westward propagation of type-1 QBWO disturbances (Fig. 9a-d), the corresponding negative geopotential height anomaly at $850 \mathrm{hPa}$ propagates westward with a cyclonic circulation (Fig. 10a-d). When the positive rainfall anomaly center is at the strongest on Day 6 
Fig. 8 Same as Fig. 7, except for type-2 disturbances. The left column is for terms averaged over $125^{\circ}-135^{\circ} \mathrm{E}$, and the right, over $150^{\circ}-160^{\circ} \mathrm{E}$

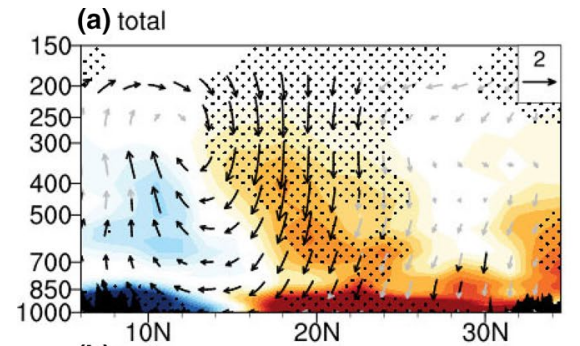

(b) $u q / x$

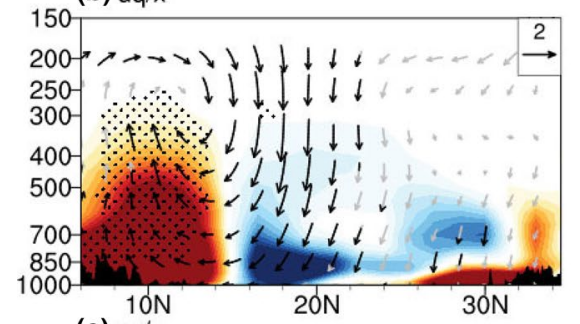

(c) $\mathrm{vq} / \mathrm{y}$

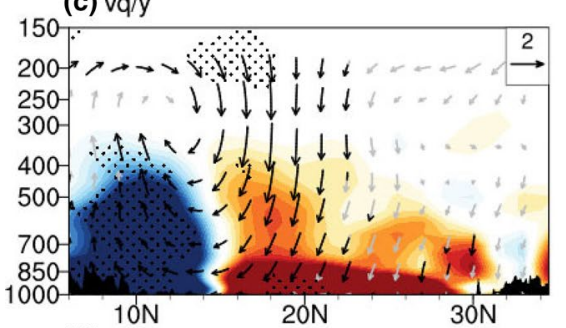

(d) $\mathrm{wq} / \mathrm{p}$

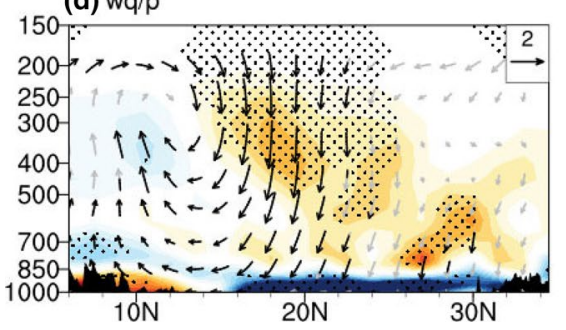

(e) total
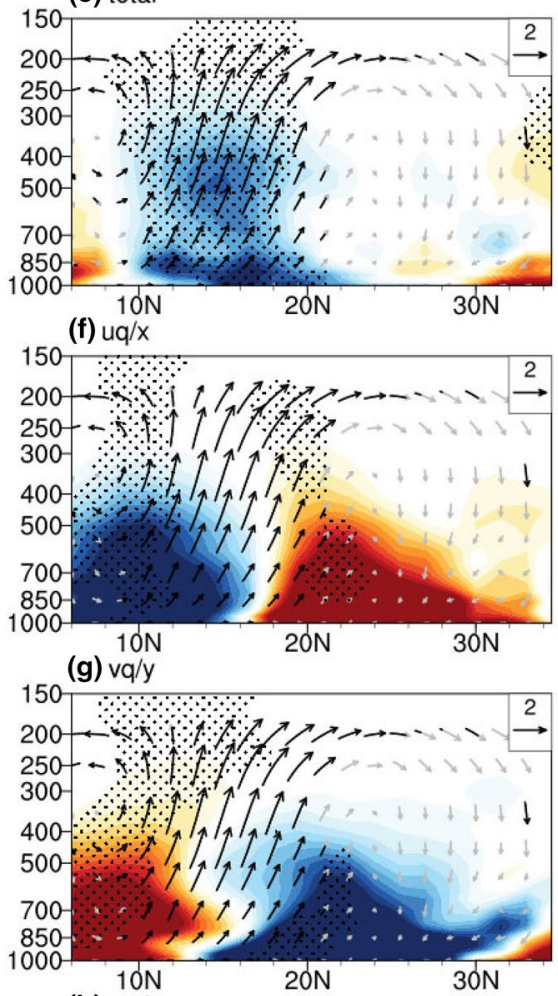

(h) $w q / p$

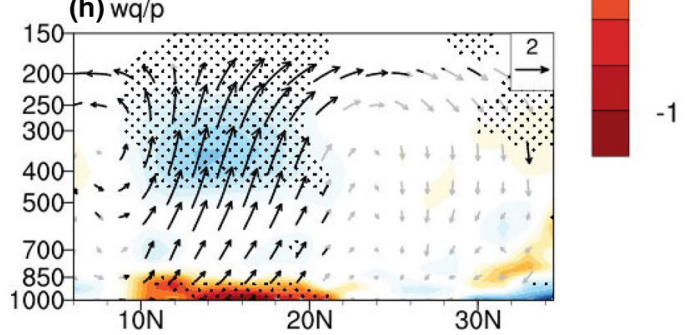

(Fig. 9d), a distinct wave train appears with alternating positive-negative height and divergence/convergence anomalies (Fig. 10d). As the positive rainfall anomaly weakens over northern Vietnam on day 8 (Fig. 9e), the negative center of the height anomaly weakens (Fig. 10e). When the negative rainfall anomaly moves westward and weakens gradually near $120^{\circ} \mathrm{E}$ (Fig. 9f-h), the positive anomaly of geopotential height also moves westward and weakens (Fig. 10f-h). With the westward propagation of type-2 QBWO disturbances (Fig. 9i-n), negative height anomalies propagate westward from the western Pacific (Fig. 10i-1) and induce wave trains on both sides of the anomaly (Fig. 10n). For the type-1 QBWO, the resulting negative height anomaly center, which is coincident with QBWO rainfall, starts at more northerly latitudes and moves gradually southward as it propagates. The negative height anomaly for type 2 disturbances starts more southward and propagates to the northwest. Geopotential height anomalies at $500 \mathrm{hPa}$ are similar to those at $850 \mathrm{hPa}$ (not shown).
A wave train is also observed in the 200-hPa geopotential height field (Fig. 11). The most significant westward-propagating wave train for type-1 QBWO events occurs on day 6 (Fig. 11d), when the positive rainfall anomaly is strongest (Fig. 9d). For type 2 QBWO events, the wave train appears to propagate northward. The mid-latitude wave train appearing as a $(-+-+)$ pattern on day $2($ Fig. $11 \mathrm{j})$ becomes a $(+-+-)$ pattern on day 8 (Fig. $11 \mathrm{~m})$.

On the 10-20-day time scale, anomalies in 850-hPa and 200-hPa height fields that are associated with QBWO also appear to be associated with intraseasonal variability in the WPSH and the SAH themselves. However, we can also examine how longer-term variability in the characteristics of WPSH and SAH affect the formation of the different types of QBWO events. Figure 12 shows the extent of the SAH represented by the contour of 12,230 gpm of 200-hPa height and that of the WPSH by the contour of $5760 \mathrm{gpm}$ of 500hPa height for both types of QBWOs in day 0. For the type-1 QBWO, the longitude span of the SAH in the upper troposphere is broad, with the easternmost point of its ridgeline 
Fig. 9 Life cycle of the type-1 (left) and type-2 (right) QBWO events shown by the 10-20-day filtered precipitation (shading, units: $\mathrm{mm}$ /day) and $850-\mathrm{hPa}$ wind (vector; units: $\mathrm{m} \mathrm{s}^{-1}$ ). Stippling indicates significant precipitation anomalies above the $95 \%$ confidence level based on a Student's $t$ test. For winds, only significant anomalies above the $95 \%$ confidence level are plotted
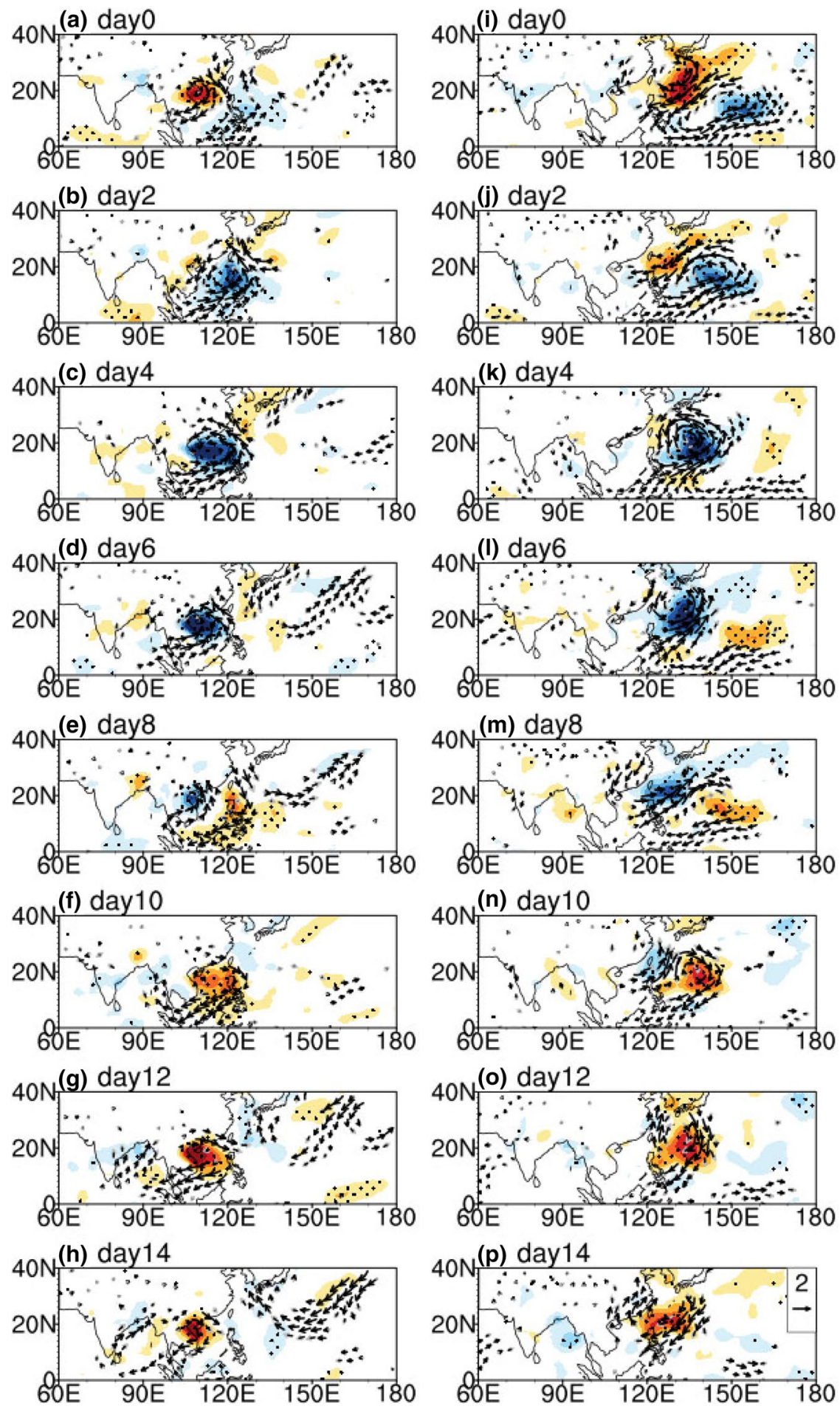

around $130^{\circ} \mathrm{E}$ (Fig. 12a). The longitude span of the WPSH in the mid-troposphere is vast as well, and the westernmost point of its ridgeline reaches the Hainan Island (Fig. 12c). The WPSH exerts a major impact on the variability of the western Pacific monsoon rainfall. Its strong westward extension is not conducive to convection over the western Pacific, but is more favorable for convection near the Philippine
Islands. It favors the propagation of the QBWO through the South China Sea to the Asian continent where it can produce rainfall anomalies (Wang et al. 2016). When type 2 QBWO events occur, the SAH (Fig. 12b) and the WPSH (Fig. 12d) are weaker. Convection is thus more active over the western Pacific, and QBWOs are generated more easily there. 
Fig. 10 Composite patterns of 10-20-day filtered 850-hPa geopotential height (shading; units: $\mathrm{gpm}$ ) and winds (vector; units: $\mathrm{m} \mathrm{s}^{-1}$ ) for type-1 (left) and type-2 (right) QBWO. Stippling indicates significant geopotential height anomalies above the $95 \%$ confidence level. Only the significant wind anomalies above the $95 \%$ confidence level are plotted
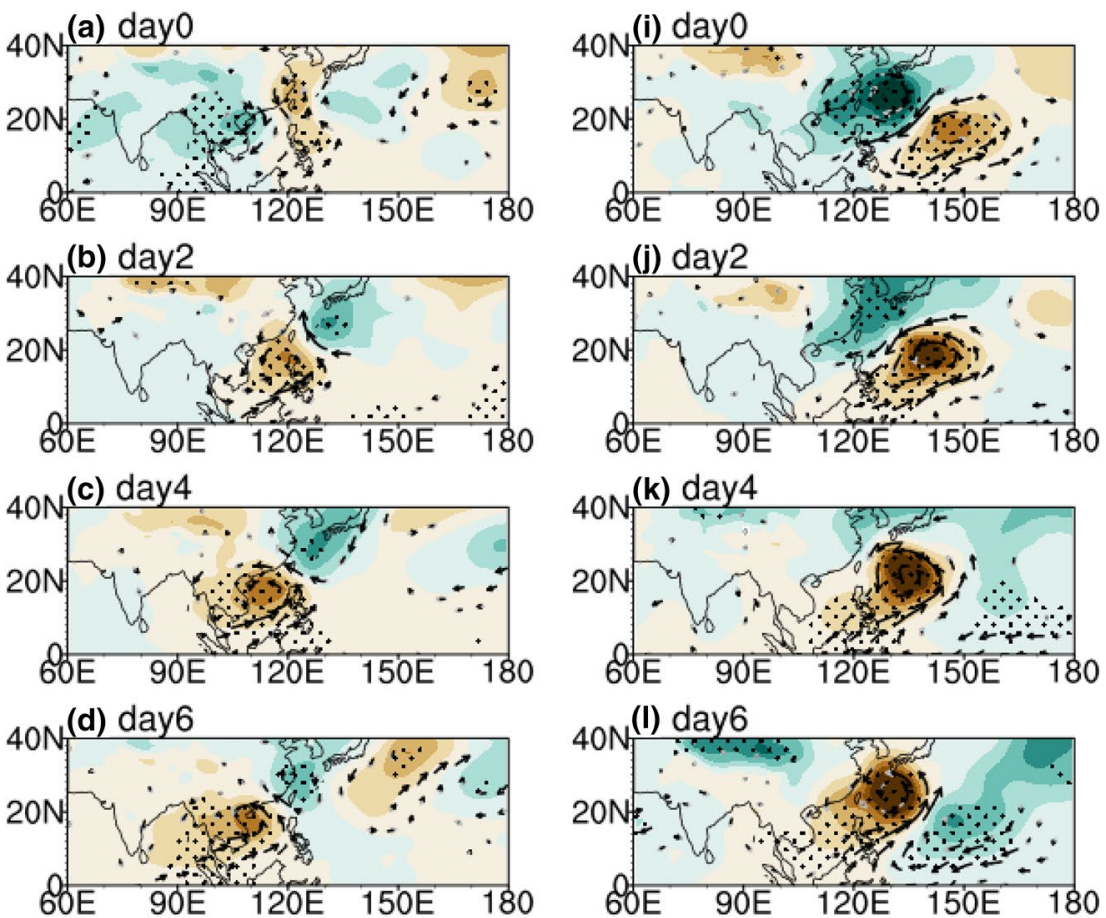

40
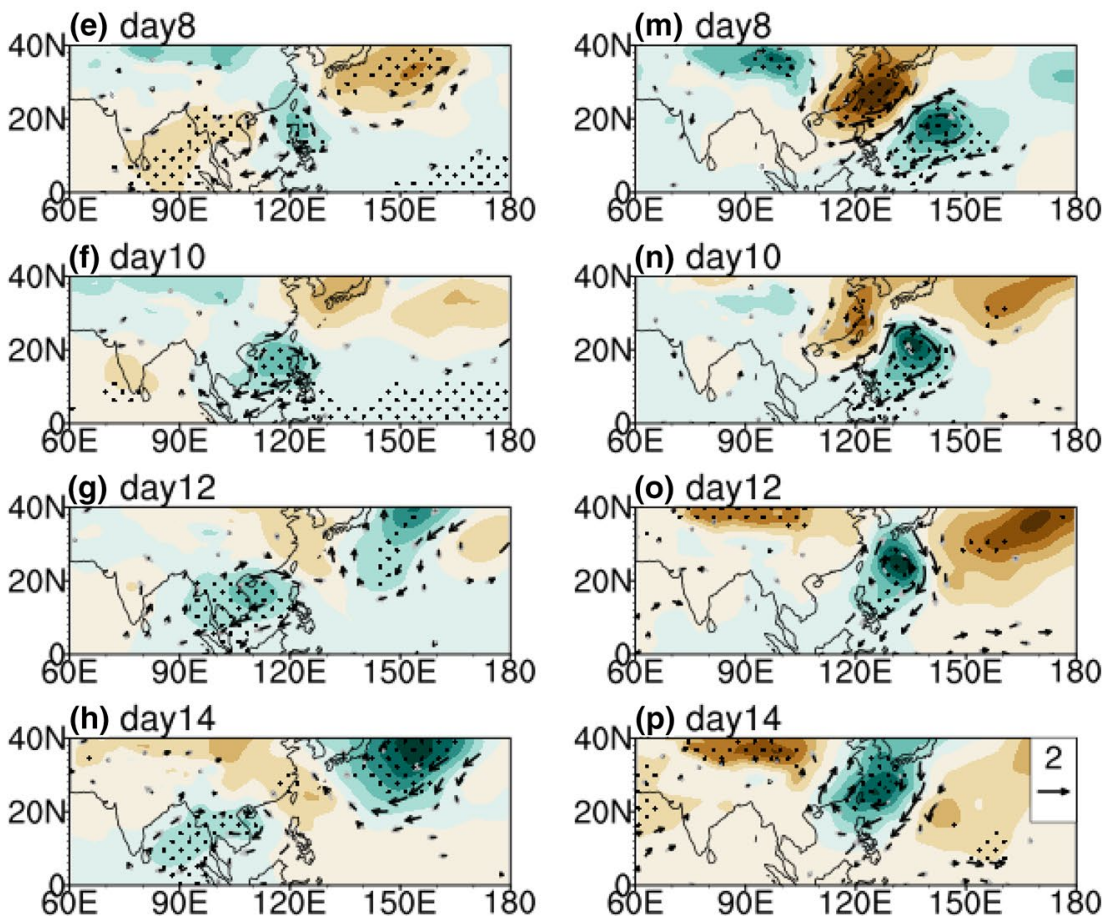

The results above suggest that the interactions between subtropical highs and QBWOs may be different at different time scales. On the 10-20-day time scale, the geopotential height anomalies associated with QBWOs perturb the WPSH and SAH circulations. The 10-20-day filtered height anomalies associated with the SAH at $200 \mathrm{hPa}$ are characterized by a northward propagation. Longer term variations in the SAH and WNSH can also affect the type of QBWO that is produced. Simultaneously stronger SAH and WPSH are more conducive to type-1 QBWO events, while simultaneously weaker SAH and WPSH are more beneficial for type-2 QBWO events. 
Fig. 11 Same as Fig. 10, except for the 200-hPa level
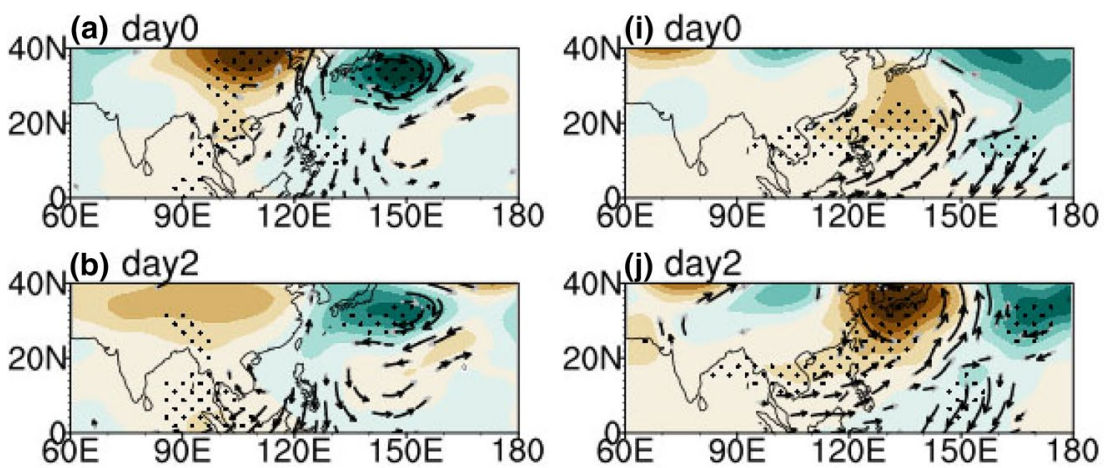

150
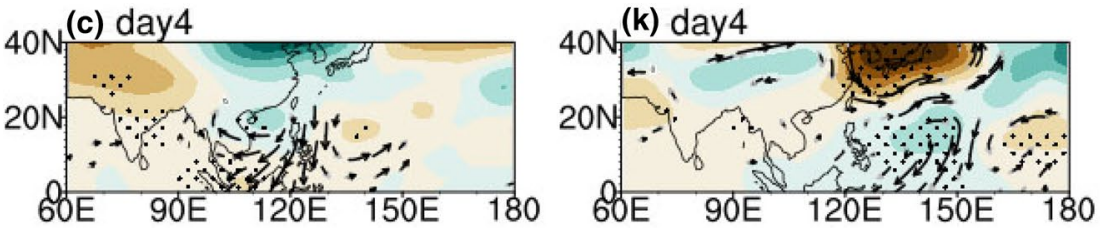

120
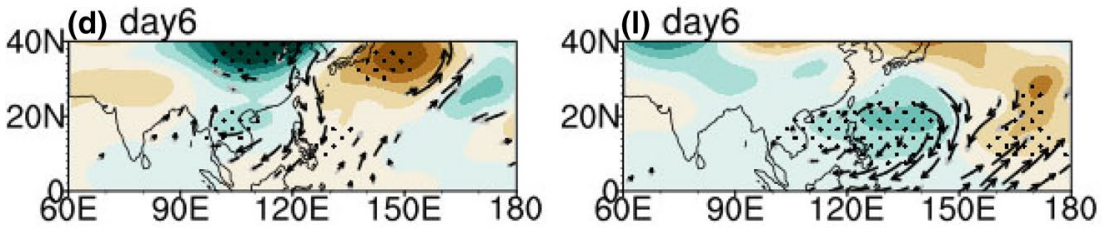

60
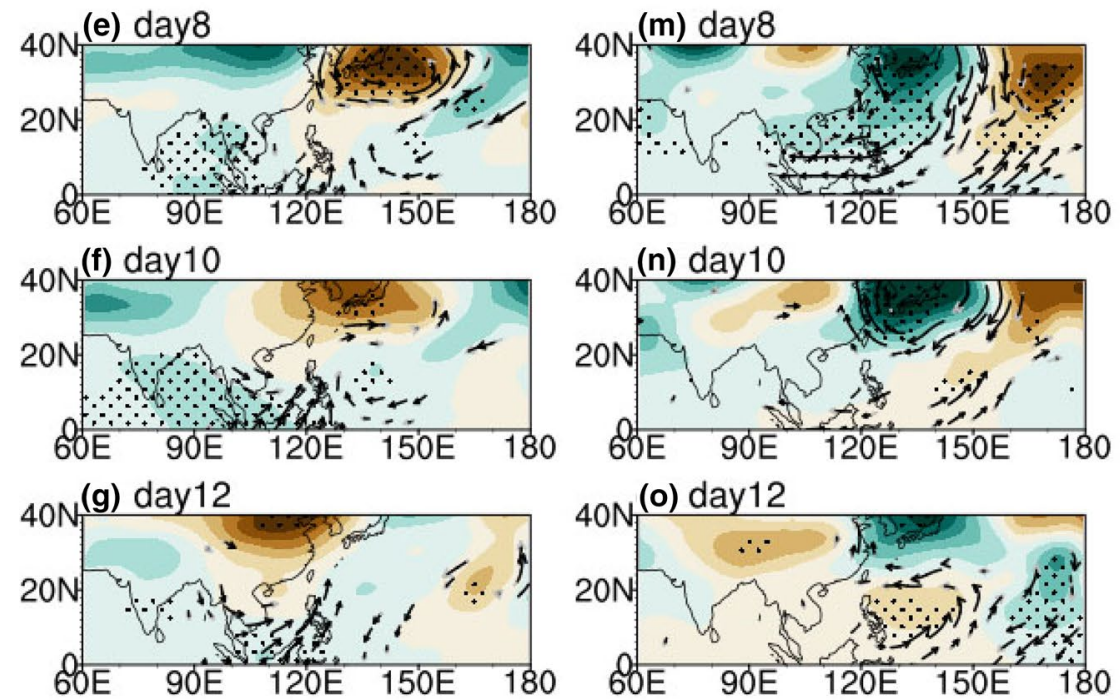

90
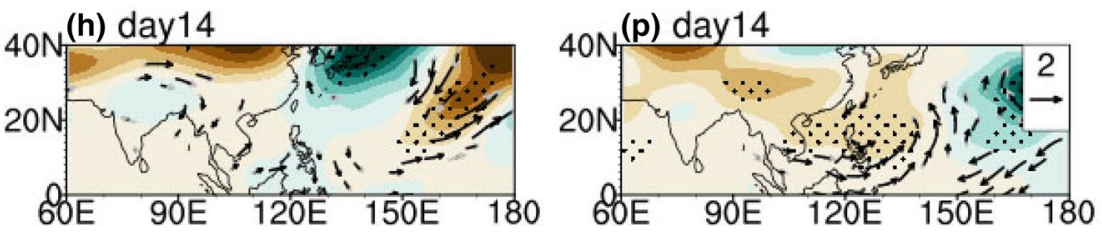

\subsection{Relationships with Pacific SST and the Madden- Julian Oscillation}

Ocean-atmosphere interactions have been hypothesized to play an important role in supplying energy to sustain convection and atmospheric circulations during the northwestward propagation of intraseasonal oscillations over the western North Pacific (Hsu and Weng 2001). Next, we analyze the background SST anomaly state when QBWO events occur. It is noted that a small positive SST anomaly is apparent over the South China Sea for type 1 disturbances (Fig. 13a), which should contribute to stronger convection in the region, allowing QBWO events to further develop and propagate westward after they cross the northern mountains of the Philippines. For type 2 disturbances (Fig. 13b), robust negative SST anomalies to the east of the Philippines would 
Fig. 12 Composite patterns of 200-hPa geopotential height (contour of 12,230 gpm; left) and 500-hPa geopotential height (contours of $5760 \mathrm{gpm}$; right) for type 1 (top) and type 2 (bottom) disturbances. The black line represents climatological values. Only the significant anomalies above the $95 \%$ confidence level are plotted
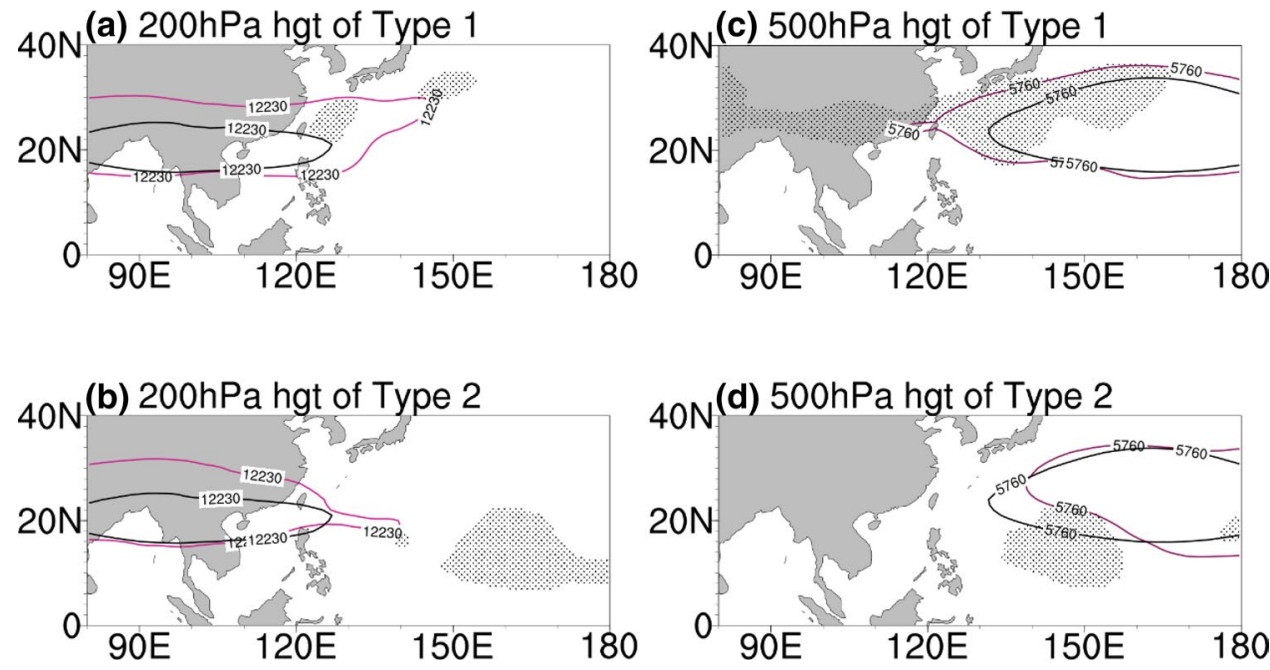

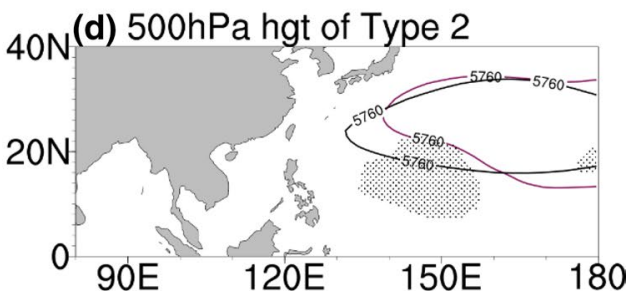

(a) SSTA of Type 1

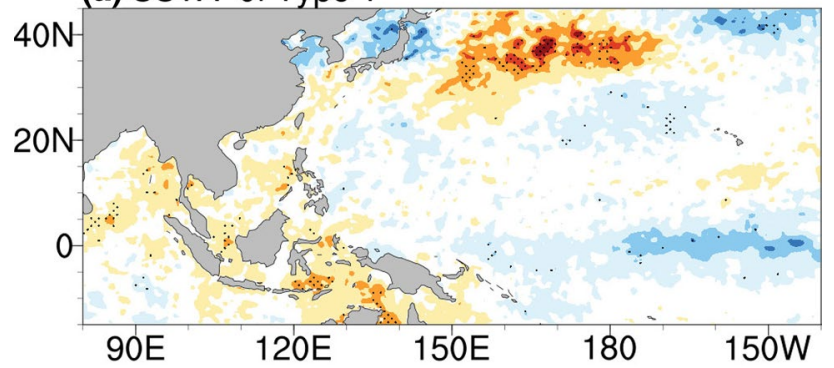

(b) SSTA of Type 2

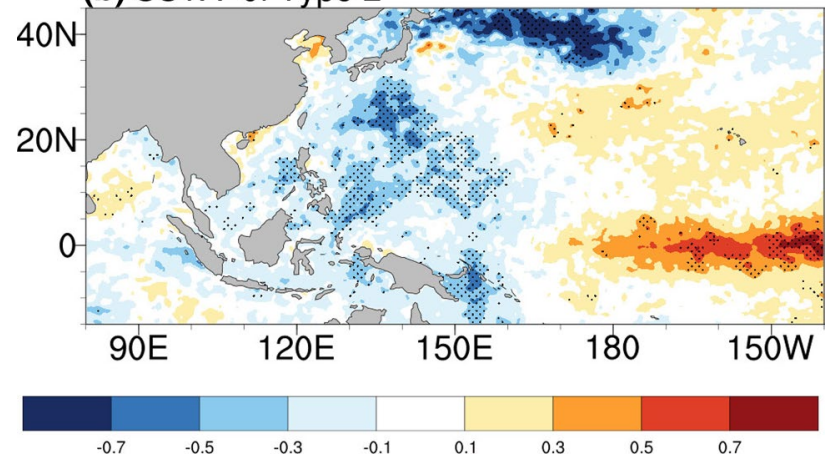

Fig. 13 Composite anomalies of SST (shading; units: ${ }^{\circ} \mathrm{C}$ ) for a type- 1 and b type-2 QBWO events during August-October. Stippling indicates significant SST anomalies above the 95\% the confidence level

inhibit convective activity, which is not conducive to the continued westward propagation and maintenance of type 2 QBWO events.

In addition to the local SST anomalies that can directly influence QBWO convection, it is worth noting that in the eastern equatorial Pacific there exist also significant positive (Fig. 13a) and negative (Fig. 13b) SST anomalies, likely reflecting El Niño-Southern Oscillation (ENSO) events. The change in monsoon ISOs with ENSO evolution has been an important research topic in recent years.
In El Niño developing summers, the 30-60-day oscillation has been suggested to be stronger than the QBWO (Wu and Cao 2017), although these results were not conclusive. Yang et al. (2008) indicated that year-to-year variations in the intensity of the QBWO and of the 30-50-day oscillation over the South China Sea were anti-correlated during June-July. Pillai and Chowdary (2015) found that the ISO characteristics such as variance, northward propagation, spatial distribution, and durations of active and break days were strongly modulated by the seasonal background anomalies over the Indo-Pacific region. El Niño phases exert a stronger impact on the 30-60-day time scale than on the 10-20-day time scale. Liu et al. (2016) found that during El Niño summers, the ISO in the western North Pacific was dominated by a higher-frequency oscillation with a period around 20-40 days, whereas during La Niña summers the ISO was dominated by lower-frequencies between 40 and 70 days. Wu and Cao (2017) argued that the feedback of surface heat flux onto the intensity of atmospheric oscillations is more prominent on the 10-20-day time scale than on the 30-60-day time scale. The 10-20-day oscillation is stronger during El Niño-developing summers, whereas the 30-60-day oscillation is stronger during La Niña decaying summers. In general, the above results suggest a role for air-sea interaction and background SST state in the occurrence of QBWO events, although the precise nature of the modulation is sometimes contradictory.

Here we address the question: During El Niño developing years, is QBWO activity in the monsoon region stronger or weaker? Given the cold tongue anomalies in the eastern Pacific Ocean in Fig. 13, we speculate that ENSO variability and associated variability in the large-scale circulation will lead to different types of QBWO events. 14 type-1 events (out of total 22 events) occur in La Niña developing summers, which are shown in Fig. 14a as blue dots. Another 11 type- 2 events (out of total 20 events) occur in El Niño 
Fig. 14 Occurrence dates for QBWO events in an RMM index phase diagram for type 1 (a) and type 2 (b) disturbances. Blue, red and green dots denote La Niña years, El Nino years, and neutral years, respectively
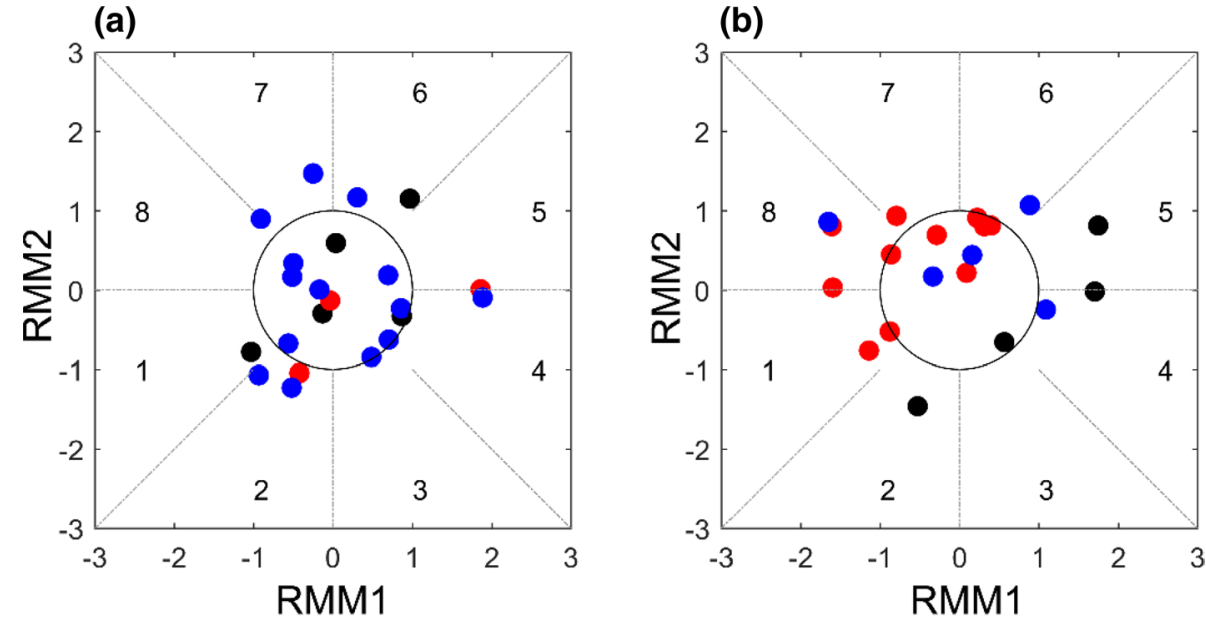

- Neutral

El Nino

- La Nina
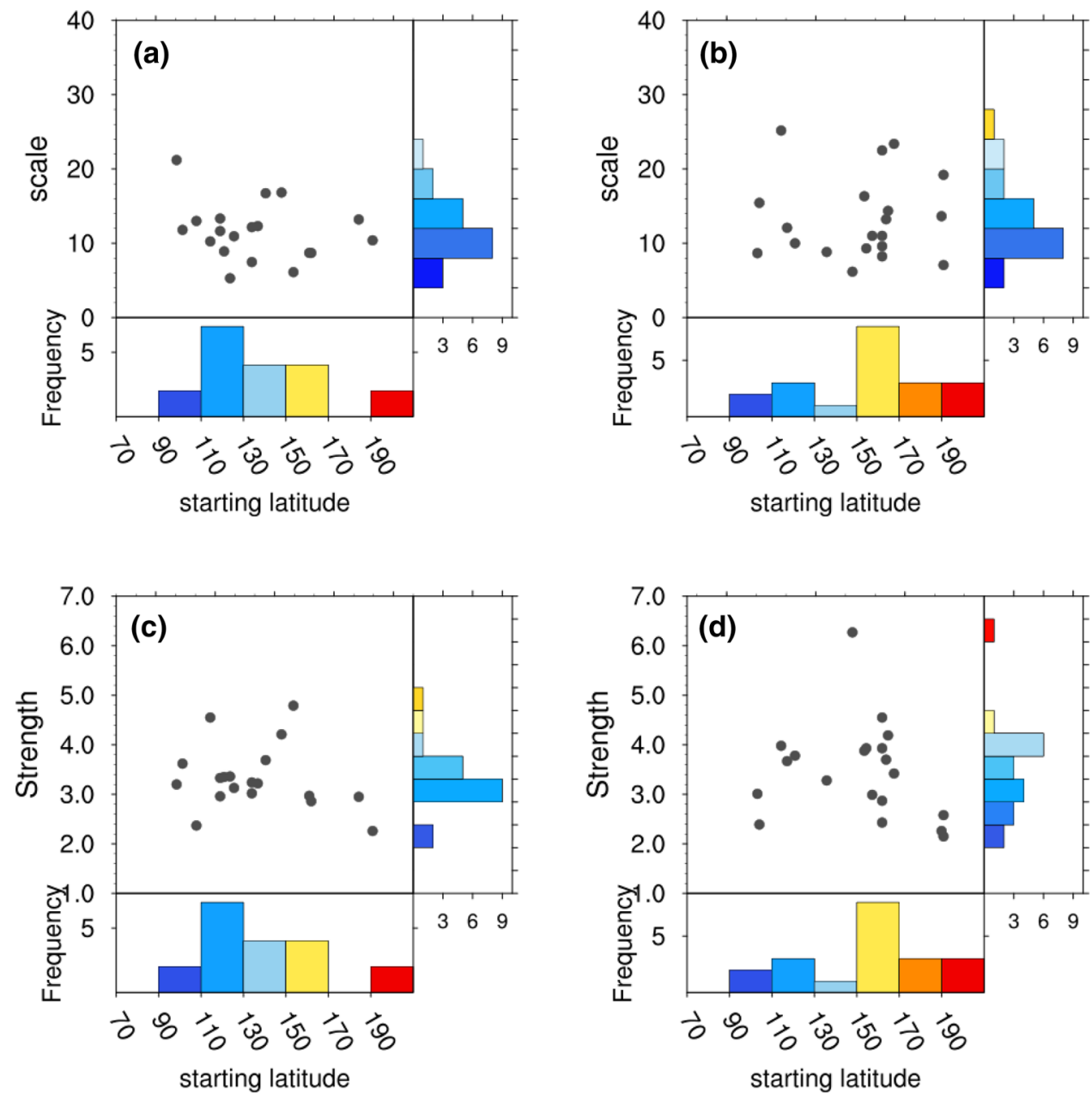

Fig. 15 Individual and joint frequency distributions of tracked QBWO events for starting longitude (units: degree) vs zonal scale (units: degree) in La Nina years (a) and El Nino years (b); and starting longitude vs mean strength (units: $\mathrm{mm} /$ day) in La Nina years (c) and El Nino years $(\mathbf{d})$ developing summers, which are shown in Fig. 14b as red dots. These results suggest that the QBWO events during ASO have a relationship with ENSO. During the development phase of ENSO, the SST anomaly in the western
Pacific may affect the occurrence of QBWO through oceanic feedback.

We further examine whether QBWO events are modulated by the MJO. For this, the phases of the RMM index on 
the days of QBWO event initiation are shown in Fig. 14. In La Niña developing summers (Fig. 14a), the type-1 QBWO events tend to occur when the MJO is in any phase. However, in El Niño developing summers (Fig. 14b), the emergence of a QBWO event appears most likely in phases 1, 6, 7 and 8 of the MJO. This suggests that when a positive MJO convective event is present over the Indian Ocean or the Maritime Continent (in phase 2, 3, 4 and 5), it is not conducive to the occurrence of QBWOs. In general, the impact of MJO on the QBWO does not appear to be substantial based on this preliminary analysis and requires further study.

To discern the impact of ENSO on the characteristics of QBWO events, the frequency distributions of QBWO characteristics are shown in Figs. 15 and 16, in which we separate the La Niña and El Niño developing summers. The first thing of note is that more events originate at around $120^{\circ} \mathrm{E}$ in La Niña developing summers while a large number of events originate near $160^{\circ} \mathrm{E}$ in El Niño developing summers (Fig. 15a, b), providing a difference perspective on the information in Fig. 13. Second, the zonal scale does not substantially change in for different ENSO phases (Fig. 15a, b). Third, the strength in La Niña developing summers is weaker ( $3 \mathrm{~mm} /$ day) on average than in El Niño developing summers ( $4 \mathrm{~mm} /$ day). Further, it is found that the propagation speed is between 3 and $10 \mathrm{~m} / \mathrm{s}$ and it has two frequency maxima (4-6 m/s and $7 \mathrm{~m} / \mathrm{s}$ ) in both La Niña and El Niño developing summers (Fig. 16a, b) which also can be found in Fig. 2a. The most frequent propagation speed in La Niña developing summers is $8 \mathrm{~m} / \mathrm{s}$ (Fig. 16a). In contrast, the most frequent propagation speed in El Niño developing summers is near $5 \mathrm{~m} / \mathrm{s}$ (Fig. 16b). Finally, it does not seem that propagation range and ENSO are strongly related (Fig. 16c, d). These results suggest that QBWO events in La Niña developing summers have a larger strength and higher propagation speed, but that ENSO does not substantially affect the QBWO events' zonal scale and propagation range.

\section{Conclusions and discussion}

The QBWO and the 30-60-day oscillation are two primary modes of intrseasonal variability in the tropical and subtropical summer monsoons. While the 30-60-day oscillation has been investigated extensively, many features of the QBWO remain unclear, especially its complex generation and propagation mechanisms. The present study is focused on the
Fig. 16 Individual and joint frequency distributions for tracked QBWO events of starting longitude (units: degree) vs propagation speed (units: $\mathrm{m} / \mathrm{s}$ ) in La Nina years (a) and El Nino years (b); and starting longitude vs propagation range (units: degree) in La Nina years (c) and El Nino years (d)
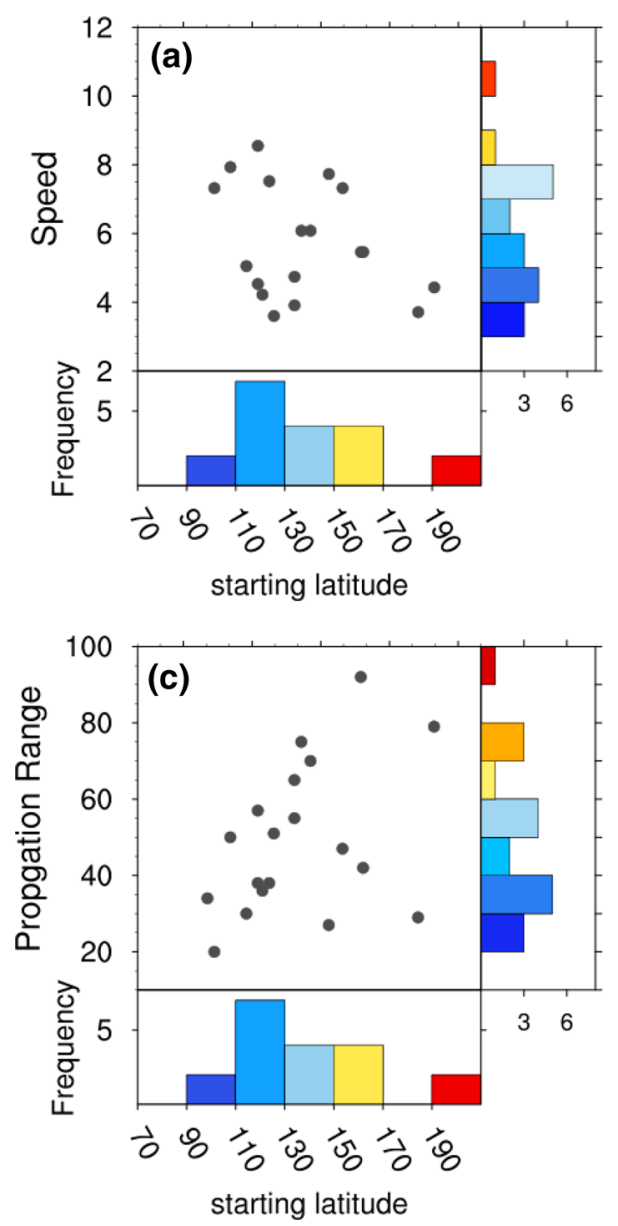
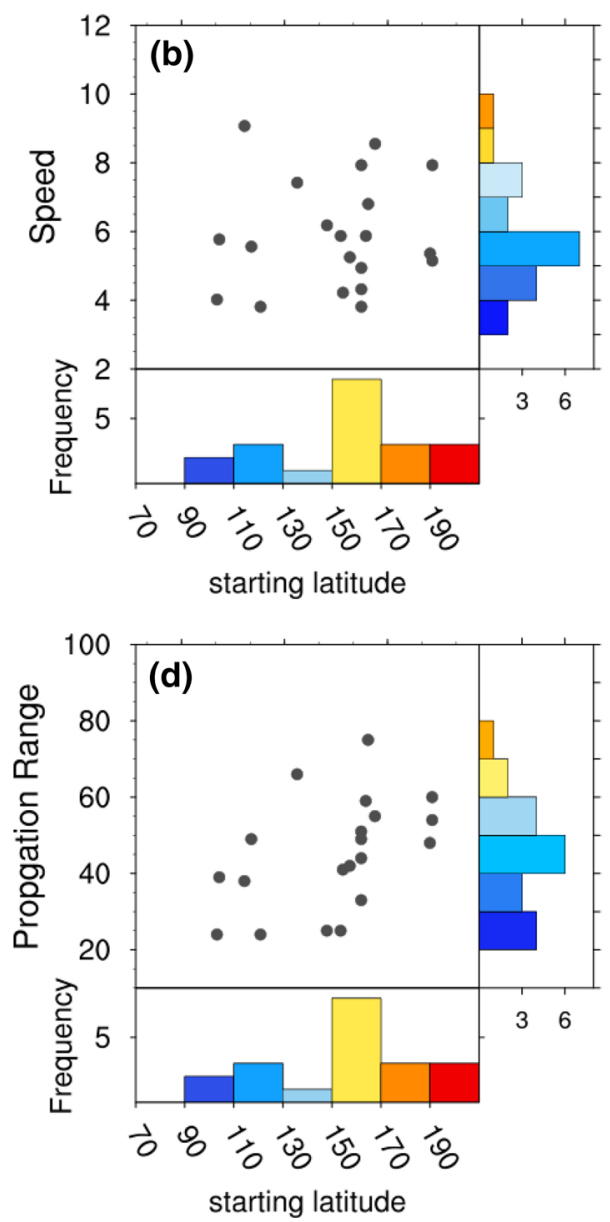
QBWO of Asian monsoon rainfall during August-October. Building on the MJO tracking algorithm of Zhang and Ling (2017), we depict the westward propagation of QBWOs over the monsoon region using an improved tracking method.

Previous studies (Yang et al. 2014; Wang et al. 2016) have compared different paths of QBWO propagation at different stages of monsoon development. Our study shows that different types of QBWO propagation can occur in the same season. The tracked QBWO events can be divided into two categories. One originates from $110^{\circ}$ to $140^{\circ} \mathrm{E}$ and exerts its influence westward to southern China. The other is characterized by initiation locations from $160^{\circ} \mathrm{E}$ to the dateline, and shows a weaker effect on mainland China. Our results suggest that environmental conditions over the South China Sea after disturbances pass through the northern mountains of the Philippines are important for determining whether these QBWO events can affect the Asian continent.

Analysis of the vertical structure of moisture flux convergence shows that the moisture source for type-1 QBWO disturbances is mainly the zonal flux component, and for type 2 disturbances the meridional flux component. The difference in moisture sources for the two types of QBWOs provides clues into their different generation mechanisms.

The SAH and the WPSH play an important role in the generation and propagation of QBWOs. On the 10-20-day timescale, both SAH and WPSH are modulated by wave trains associated with the QBWOs. WPSH geopotential height anomalies appear most strongly modulated by westward-propagating QBWO wave trains. However, the SAH is primarily modulated by QBWO wave trains that propagate northward. Associated with longer timescale fluctuations of the SAH and WPSH, type-1 QBWO events are more likely to occur when both SAH and WPSH are stronger, while type-2 QBWO events correspond to simultaneously weaker SAH and WPSH. Previous studies (e.g., Tao and Xu 1962; Tao and Wei 2006) have suggested that the SAH and the WPSH were closely related to each other. This coupling of the SAH and WNPSH strongly modulates the meridional circulation, vertical motion, and summer monsoon rainfall that affect QBWOs, although the responsible physical mechanisms are not entirely clear. The multi-scale dynamic processes linking SAH and WPSH to the QBWO events originating in the western Pacific are an issue that deserves further investigation.

More generally, the physical mechanisms underlying QBWO dynamics and it variability are still not fully understood. It is believed that the QBWO is an intrinsic mode of the tropical atmosphere (Goswami and Mathew 1994; Chatterjee and Goswami 2006), and may be supported by an evaporation-wind feedback under conditions of mean westerly flow or convective heating induced by boundary layer convergence. However, it has also been suggested that feedbacks among convection, Rossby wave dynamics, and the low-level circulation are crucial in maintaining observed QBWO structure (Wen and Zhang 2008). SST anomalies are important for determining convection activity and are closely related to the origin and development of intraseasonal oscillations. Our study indicates that SST anomalies in the South China Sea to the west of the Philippines may be an important factor for the occurrence of different types of QBWO events. However, the air-sea interaction processes by which the SST anomalies affect QBWO propagation needs further investigation.

A recent study by Liu et al. (2016) on differences in ISO activity over the South China Sea and the western Pacific during different stages of ENSO showed that during El Niño developing summers the ISO is dominated by a higher-frequency oscillation with a period around 20-40 days, whereas during La Niña developing summers the ISO is dominated by a lower-frequency period around 40-70 days. On shorter timescales, Wu and Cao (2017) found that the 10-20-day oscillation was enhanced during El Niño developing summers, whereas the 30-60-day oscillation was enhanced during La Niña decaying summers. Our results complement the work above and show that during August-October the type-1 QBWO events are more likely to occur in La Niña developing summers, and the type-2 QBWO events more likely in El Niño developing summers, especially during phases 1 and $6-8$ of the MJO.

Based on the above results, we can confidently say that the occurrence of type-1 QBWO events affects rainfall over the Asian continent. Thus, the simultaneous enhancement of $\mathrm{SAH}$ and WPSH can be considered as a precursor for QBWO events that affect the Asian continent, which would be useful information for short-term forecasts. The SST in the South China Sea is also an important factor for whether QBWOs reach Asian, and how such SST variability affects QBWO characteristics deserves further investigations.

Acknowledgements We appreciate several discussions with Prof. Mingfang Ting at the Columbia University and Dr. Mingting Li at the Sun Yat-sen University. The comments from two anonymous reviewers improved the overall quality of the paper. The study was supported by the National Key Research and Development Program of China (2016YFA0602703), the National Natural Science Foundation of China (Grants 41030020, 41705030, 41661144019, 41690123, and 41690120), the "111-Plan" Project of China (Grant B17049), and the Jiangsu Collaborative Innovation Center for Climate Change. EDM was also supported by Office of Naval Research Grant N00014-16-1-3087.

Open Access This article is distributed under the terms of the Creative Commons Attribution 4.0 International License (http://creativeco mmons.org/licenses/by/4.0/), which permits unrestricted use, distribution, and reproduction in any medium, provided you give appropriate credit to the original author(s) and the source, provide a link to the Creative Commons license, and indicate if changes were made. 


\section{References}

Annamalai H, Slingo JM (2001) Active/break cycles: diagnosis of the intraseasonal variability of the Asian Summer Monsoon. Clim Dyn 18:85-102

Banzon VF, Reynolds RW (2013) Use of WindSat to extend a microwave-based daily Optimum Interpolation Sea Surface Temperature time teries. J Clim 26:2557-2562

Chatterjee P, Goswami BN (2006) Structure, genesis and scale selection of the tropical quasi-biweekly mode. Q J R Meteorol Soc 130:1171-1194

Chen T-C, Chen J (1993) The 10-20-day mode of the 1979 Indian monsoon: its relation with the time variation of monsoon rainfall. Mon Weather Rev 121:2465-2482. https://doi.org/10.1175/15200493(1993)121\%3c2465:TDMOTI\%3e2.0.CO;2

Chen T-C, Chen J (1995) An observational study of the South China Sea monsoon during the 1979 summer: onset and life cycle. Mon Weather Rev 123:2295-2318

Chen G, Sui C (2010) Characteristics and origin of quasi-biweekly oscillation over the western North Pacific during boreal summer. J Geophys Res 115:D14113. https://doi.org/10.1029/2009JD013389

Chen T-C, Yen M, Weng S (2000) Interaction between the summer monsoons in East Asia and the South China Sea: intraseasonal monsoon modes. J Atmos Sci 57:1373-1392

Duchon CE (1979) Lanczos filtering in one and two dimensions. J Appl Meteorol 18:1016-1022

Fukutomi Y, Yasunari T (1999) 10-25 day intraseasonal variations of convection and circulation over East Asia and western North Pacific during early summer. J Meteorol Soc Jpn 77:753-769

Goswami P, Mathew V (1994) A mechanism of scale selection in tropical circulation at observed intraseasonal frequencies. J Atmos Sci 51:3155-3166

Gottschalck J, Roundy PE, Schreck CJ III et al (2013) Large-scale atmospheric and oceanic conditions during the 2011-12 DYNAMO Field Campaign. Mon Weather Rev 141:4173-4196. https://doi.org/10.1175/MWR-D-13-00022.1

Hsu H, Weng C (2001) Northwestward propagation of the intraseasonal oscillation in the western North Pacific during the boreal summer: structure and mechanism. J Clim 14:3834-3850

Huffman GJ, Adler RF, Morrissey MM et al (2001) Global precipitation at one-degree daily resolution from multisatellite observations. J Hydrometeorol 2:36-50

Huffman GJ, Bolvin DT, Adler RF (2016) GPCP version 1.2 onedegree daily precipitation data set. Research Data Archive at the National Center for Atmospheric Research, Computational and Information Systems Laboratory, Boulder

Jia X, Yang S (2013) Impact of the quasi-biweekly oscillation over the western North Pacific on East Asian subtropical monsoon during early summer. J Geophys Res-Atmos 118:4421-4434. https://doi. org/10.1002/jgrd.50422

Kemball-Cook S, Wang B (2001) Equatorial waves and air-sea interaction in the boreal summer intraseasonal oscillation. J Clim 14:2923-2942

Kerns BW, Chen SS (2016) Large-scale precipitation tracking and the MJO over the Maritime Continent and Indo-Pacific warm pool. J Geophys Res 121:8755-8776

Keshavam RN (1971) Power spectra of large-scale disturbances of Indian summer monsoon. Bull Am Meteorol Soc 52:796

Keshavamurty RN (1972) On the vertical tilt of monsoon disturbances. J Atmos Sci 29:993-995

Kikuchi K, Wang B (2009) Global perspective of the quasi-biweekly oscillation. J Clim 22:1340-1359

Kiladis GN, Chris D, Thorncroft Nicholas, Hall MJ (2006) Threedimensional structure and dynamics of African easterly waves. Part I: Observations. J Atmos Sci 63:2212-2230
Lau KH, Lau NG (1992) The energetics and propagation dynamics of tropical summertime synoptic-scale disturbances. Mon Weather Rev 120:2523-2539. https://doi.org/10.1175/15200493(1992)120\%3c2523:TEAPDO\%3e2.0.CO;2

Lau KM, Yang GJ, Shen SH (1988) Seasonal and intraseasonal climatology of summer monsoon rainfall over East Asia. Mon Weather Rev 116:18-37

Lee JY, Wang B, Wheeler MC et al (2013) Real-time multivariate indices for the boreal summer intraseasonal oscillation over the Asian summer monsoon region. Clim Dyn 40:493-509

Li C, Li T, Lin A et al (2015) Relationship between summer rainfall anomalies and sub-seasonal oscillations in South China. Clim Dyn 44:423-439

Lin H (2012) Monitoring and predicting the intraseasonal variability of the East Asian-western North Pacific summer monsoon. Mon Weather Rev 141:1124-1138

Ling J, Zhang C, Wang S, Li C (2017a) A new interpretation of the ability of global models to simulate the MJO. Geophys Res Lett 44:5798-5806. https://doi.org/10.1002/2017GL073891

Ling J, Li C, Li T et al (2017b) Challenges and opportunities in MJO studies. Bull Am Meteorol Soc 98:ES53-ES56. https://doi. org/10.1175/BAMS-D-16-0283.1

Liu F, Li T, Wang H et al (2016) Modulation of boreal summer intraseasonal oscillations over the western North Pacific by ENSO. J Clim 29:7189-7201

Maloney ED, Jiang X, Xie S, Benedict JJ (2014) Process-oriented diagnosis of East Pacific Warm Pool intraseasonal variability. J Clim 27:6305-6324. https://doi.org/10.1175/JCLI-D-14-00053.1

National Climatic Data Center NNUS (2007) NOAA optimum interpolation $1 / 4$ degree daily sea surface temperature analysis, version 2. Research data archive at the National Center for Atmospheric Research, Computational and Information Systems Laboratory, Boulder

Neelin JD, Held IM (1987) Modeling tropical convergence based on the moist static energy budget. Mon Weather Rev 115:3-12

Pillai PA, Chowdary JS (2015) Indian summer monsoon intra-seasonal oscillation associated with the developing and decaying phase of El Niño. Int J Climatol 36:1846-1862

Reynolds RW, Smith TM, Liu C et al (2007) Daily high-resolution-blended analyses for sea surface temperature. J Clim 20:5473-5496

Rydbeck AV, Maloney ED (2015) On the convective coupling and moisture organization of East Pacific easterly waves. J Atmos Sci 72:3850-3870

Simmons A, Uppala S, Dee D, Kobayashi S (2007) ERA-Interim: New ECMWF reanalysis products from 1989 onwards. ECMWF

Tao S, Wei J (2006) The westward and northward advance of the subtropical high over the west Pacific in summer. Chin J Appl Meteorol 17:513-525 (in Chinese)

Tao S, Xu S (1962) Circulation characteristics in association with persistent drought and flood in the Yangtze-Huaihe River reaches. Acta Meteorol Sin 32(1):1-18 (in Chinese)

Wang B, Huang F, Wu Z et al (2009) Multi-scale climate variability of the South China Sea monsoon: a review. Dyn Atmos Oceans $47: 15-37$

Wang X, Chen G, Huang R (2016) Different characteristics of the quasi-biweekly oscillation over the South China Sea in two boreal summer stages. Theor Appl Climatol 126:1-13

Wang M, Wang J, Duan A (2017a) Propagation and mechanisms of quasi-biweekly oscillation over the Asian summer monsoon region. J Meteorol Res 31(2):321-335. https://doi.org/10.1007/ s13351-017-6131-5

Wang Z, Ding Y, Lu M, Zhou B, Yang S, Jiang X, Ke Z (2017b) Intraseasonal variability and predictability of the subtropical Asian summer rain band. Int J Climatol 37(11):4119-4130 
Wen M, Zhang R (2008) Quasi-biweekly oscillation of the convection around Sumatra and low-level tropical circulation in boreal spring. Mon Weather Rev 136:189-205

Wen M, Li T, Zhang R, Qi Y (2010) Structure and origin of the quasibiweekly oscillation over the tropical Indian Ocean in boreal spring. J Atmos Sci 67:1965-1982

Wheeler MC, Hendon HH (2004) An all-season real-time multivariate MJO index: development of an index for monitoring and prediction. Mon Weather Rev 132:1917-1932

Wu R, Cao X (2017) Relationship of boreal summer 10-20-day and 30-60-day intraseasonal oscillation intensity over the tropical western North Pacific to tropical Indo-Pacific SST. Clim Dyn 48:3529-3546

Yang J, Wang B, Wang B (2008) Anticorrelated intensity change of the quasi-biweekly and 30-50-day oscillations over the South China Sea. Geophys Res Lett 35:L16702. https://doi.org/10.1029/2008G L034449

Yang J, Bao Q, Wang B et al (2014) Distinct quasi-biweekly features of the subtropical East Asian monsoon during early and late summers. Clim Dyn 42:1469-1486
Yokoi S, Satomura T, Matsumoto J (2007) Climatological characteristics of the intraseasonal variation of precipitation over the Indochina Peninsula. J Clim 20:5301-5315

Zhang C, Ling J (2017) Barrier effect of the Indo-Pacific Maritime Continent on the MJO: perspectives from tracking MJO precipitation. J Clim 30:3439-3459

Zhang C, Gottschalck J, Maloney ED et al (2013) Cracking the MJO nut. Geophys Res Lett 40:1223-1230. https://doi.org/10.1002/ grl.50244

Publisher's Note Springer Nature remains neutral with regard to jurisdictional claims in published maps and institutional affiliations. 